$5-19-2020$

\title{
The Impact of Winter Storms on Sediment Transport Through a Narrow Strait, Bohai, China
}

\author{
Chenghao Wang \\ Zhiqiang Liu \\ Courtney K. Harris \\ Virginia Institute of Marine Science \\ et al
}

Follow this and additional works at: https://scholarworks.wm.edu/vimsarticles

Part of the Oceanography Commons

\section{Recommended Citation}

Wang, Chenghao; Liu, Zhiqiang; Harris, Courtney K.; and et al, The Impact of Winter Storms on Sediment Transport Through a Narrow Strait, Bohai, China (2020). Journal of Geophysical Research: Oceans, 125(6), e2020JC016069.

https://doi.org/10.1029/2020JC016069

This Article is brought to you for free and open access by the Virginia Institute of Marine Science at W\&M ScholarWorks. It has been accepted for inclusion in VIMS Articles by an authorized administrator of W\&M ScholarWorks. For more information, please contact scholarworks@wm.edu. 


\section{JGR Oceans}

\section{RESEARCH ARTICLE 10.1029/2020JC016069 \\ The Impact of Winter Storms on Sediment Transport Through a Narrow Strait, Bohai, China}

Key Points:

- Winter storms can generate low-frequency oscillations of barotropic flows accompanied by sea surface height fluctuations in Bohai Strait

- Both local wind and wind-triggered coastal trapped waves are responsible for exchange flow variations at synoptic time scales

- The combination of intensified wave motion and exchange flows strongly alters the pattern and quantity of the sediment flux in Bohai Strait

Correspondence to:

J. Xu,

xujp@sustech.edu.cn

Citation:

Wang, C., Liu, Z., Harris, C. K., Wu, X., Wang, H., Bian, C., et al. (2020). The impact of winter storms on sediment transport through a narrow strait, Bohai, China. Journal of Geophysical Research: Oceans, 125, e2020JC016069. https://doi.org/10.1029/2020JC016069

Received 12 JAN 2020

Accepted 11 MAY 2020

Accepted article online 19 MAY 2020

(C)2020. American Geophysical Union. All Rights Reserved.

\author{
Chenghao Wang ${ }^{1}\left(\mathbb{D}\right.$, Zhiqiang Liu ${ }^{2}$, Courtney K. Harris ${ }^{3}$ (D) Xiao Wu ${ }^{1,5}\left(\mathbb{D}\right.$, Houjie Wang ${ }^{1,5}$ (D), \\ Changwei Bian ${ }^{4,5}\left(\mathbb{D}\right.$, Naishuang $\mathrm{Bi}^{1,5}$, Haiqin Duan ${ }^{1}$, and Jingping $\mathrm{Xu}^{2,5}$ (D) \\ ${ }^{1}$ College of Marine Geosciences, Key Laboratory of Submarine Geosciences and Prospecting Techniques, Ocean \\ University of China, Qingdao, China, ${ }^{2}$ Department of Ocean Science and Engineering, Southern University of Science and \\ Technology, Shenzhen, China, ${ }^{3}$ Virginia Institute of Marine Science, William and Mary, Gloucester Point, VA, USA, \\ ${ }^{4}$ Physical Oceanography Laboratory/CIMST, Ocean University of China, Qingdao, 266100, China, ${ }^{5}$ Laboratory for Marine \\ Geology, Qingdao National Laboratory for Marine Science and Technology (QNLM), Qingdao, 266100, China
}

\begin{abstract}
The Yellow River is one of the most significant sources of terrestrial sediment to the global seas, and the Bohai Strait is the only pathway that delivers Yellow River-derived sediments from the shallow Bohai Sea to the Yellow Sea. To investigate sediment transport processes through the strait under the influence of storms (strong northerly winds) that frequently occur in winter, we deployed two sets of observing platforms equipped with Acoustic Doppler Current Profilers (ADCP) and a suite of other sensors in the strait in January 2018. Aided by a system of high-resolution models, we reconstructed sediment dynamics in response to the strong northerly wind of a winter storm. Model results show that the instantaneous suspended sediment flux (SSF) is highly aligned with tidal currents, while the net sediment flux has a clear dependence on variations in exchange flow and sediment resuspension. Enhanced coastal currents, intensified wave motions, and higher suspended sediment concentrations indicate that the through-strait sediment flux during outflows is greater than during inflow conditions. Such SSF asymmetries are believed responsible for the net sediment export through the Bohai Strait in wintertime. Diagnostic analyses provided insights into the dynamic mechanisms of exchange flow variations influenced by both the strong northerly winds and the wind-triggered coastal trapped waves in the shallow, narrow strait via geostrophic effects. This study highlights the importance of storm-induced horizontal exchange processes in a coupled bay-shelf system.
\end{abstract}

Plain Language Summary The aim of this study is to characterize the dominant processes that control net wintertime sediment fluxes through a narrow strait. Flows, waves, and sediment concentration were measured in the strait during a winter storm. A well-validated model showed that wintertime flows in the strait are dominated by alternating, strait-wide inflow and outflow. Occasionally, however, inflows and outflows are concurrent over different sections of the strait. Based on a numerical model, our calculations of sediment flux for the entire winter revealed that large net sediment flux occurred when both winds and waves were strong. These results provide a better understanding of how sediment transport in a bay-shelf system has driven by both local and remote forcing mechanisms.

\section{Introduction}

The quantification of sediment dispersal and transport on continental margins is often challenging due to the involvement of multiple physical forcing mechanisms at various spatial and temporal scales (Geyer \& MacCready, 2014; Huthnance, 1995). Strongly intensified meteorological events such as storms are known to be capable of profoundly impacting seabed forcing, enhancing the erosion, transport, and deposition processes of coastal sediments. The potential impact of storms on sediment transport has been extensively studied in many continental shelf settings such as sand beaches or banks (Fairley et al., 2016; Hill et al., 2004), estuarine regimes (Flores et al., 2017; Nowacki \& Ganju, 2018), coastal embayments (Maio et al., 2016; Warner, Butman, et al., 2008), and inner/mid shelves (Li et al., 2015, 2017; Wright et al., 1994). As highlighted by these studies, storms can facilitate sediment transport through a combination of localized resuspension and horizontal advection. On the one hand, storms can enhance the bottom shear stress by wave-current interaction, resulting in intensive sediment resuspension. On the other hand, storms are 
responsible for the synoptic variations of subtidal flow (also known as exchange flow or residual circulation) that determines the primary shelf-scale sediment transport pathways.

In a coupled bay-shelf system, the open ocean is connected through a strait or channel with a shallow semi-enclosed embayment where rivers usually deliver large volumes of freshwater and terrigenous sediments. Examples such as the Chesapeake Bay and Massachusetts Bay illustrate that sediment transport processes in these systems exhibit complicated behavior in response to wind-induced remote and local impacts (Warner et al., 2008; Xie et al., 2018). The high coherence between local wind speed, significant wave height, and suspended sediment concentration (SSC) in shallow bays indicate the overwhelming importance of storms in sediment resuspension (Nowacki \& Ganju, 2018). Additionally, the wind effect on exchange flow variations has been extensively studied since the discovery that wind-driven currents can be at times much larger than the density-induced gravitational flows in coastal marine systems (Wang \& Elliott, 1978). Remote winds over continental shelf can also generate oceanic upwelling and downwelling that not only strongly impact the barotropic conditions in coastal regions but also facilitate cross-shelf net sediment transport. More attention has been recently paid to the role that coastal trapped waves (CTWs) play in inducing exchange processes (Gutiérrez et al., 2014). CTWs generated by storms over a continental shelf may propagate and impose sea surface height (SSH) setup or set-down in a coastal region, largely accounting for the subtidal SSH and exchange flow variabilities at the bay-shelf and estuary-shelf junction, that is, straits, or the mouth of fjords and gulfs (Cottier et al., 2010; Wright et al., 1987). For example, Inall et al. (2015) showed that CTWs are dominant agents of flow variability and significant contributors to exchange processes in a fjord/shelf system, exceeding wind, estuarine, and tidal effects. Therefore, in a bay-shelf system, CTWs also play an important role of cross-shelf sediment exchange as a remotely controlled mechanism.

The Bohai Strait is the only passage connecting the shallow Bohai Sea and the open Yellow Sea, thus playing an important role in sediment exchange between the coupled marginal seas. The massive fine-grained sediments from the Yellow River is widely recognized as a major source that dominated sedimentation across the Bohai and Yellow Seas (Milliman \& Meade, 1983; Saito et al., 2001). Based on geological and geophysical investigations, Yang and Liu (2007) revealed a unique Yellow River-derived, mud clinoform associated with the Bohai Strait and around the eastern tip of the Shandong Peninsula in the Yellow Sea (Figure 1b). It indicates that the Yellow River-derived sediments can be transported over a long distance (more than $350 \mathrm{~km}$ from the present river mouth) to pass through the Bohai Strait and reach the deep-water region of the Southern Yellow Sea (Figure 1b). For decades, considerable attention has been paid to explore the water exchange, sediment budget, and transport pathways through the Bohai Strait. Early estimation of strait sediment fluxes was largely based on CTD (conductivity, temperature, and depth) observations at limited sites (Martin et al., 1993). Hydrographical surveys and satellite images revealed that the intensity of sediment transport from the shallow Bohai Sea to the open Yellow Sea through the narrow strait is stronger in winter than in summer due to the monsoon activities (Bi et al., 2011; Yang et al., 2011). Models driven by monthly or seasonally averaged meteorological forcing qualitatively charted the sediment transport pathways (Bian et al., 2013; Lu et al., 2011). Subsequently, a coupled current-wave model manifested that mud deposits formed farther away from river mouths are results of local weak bottom stresses and circulation patterns (Zeng et al., 2015). Recent studies show that the exchange flow in the Bohai Strait features synoptic current fluctuations, which are more complicated and unstable associated with winter storms (Ding et al., 2019). A well-designed phase averaging method (PAM) survey in the Bohai Strait exhibits a different character that massive sediment is transported from the Yellow Sea to the Bohai Sea after a northerly wind event (Wu et al., 2019a).

Previous investigations have elucidated that sediment transport through the strait is closely associated with winter storms. However, the underlying mechanisms of hydrodynamic processes (e.g., variation in exchange flows) and net sediment fluxes across the strait are still not well understood. First, marine processes in previous sediment models were simplistic, in particular, ignoring either the influence of strong winter storms or the regional sediment distribution on the seabed. Second, field observations either by cruise surveys or time-series recording were rather limited during strong wind conditions. As research on sediment transport gradually shifts from qualitative to quantitative, it is necessary to conduct systematic in situ observations and combine a coupled wave-current-sediment model to explore and quantify the flow exchange, the suspended sediment flux (SSF), and dominant transport mechanisms in the Bohai Strait. 
(a)

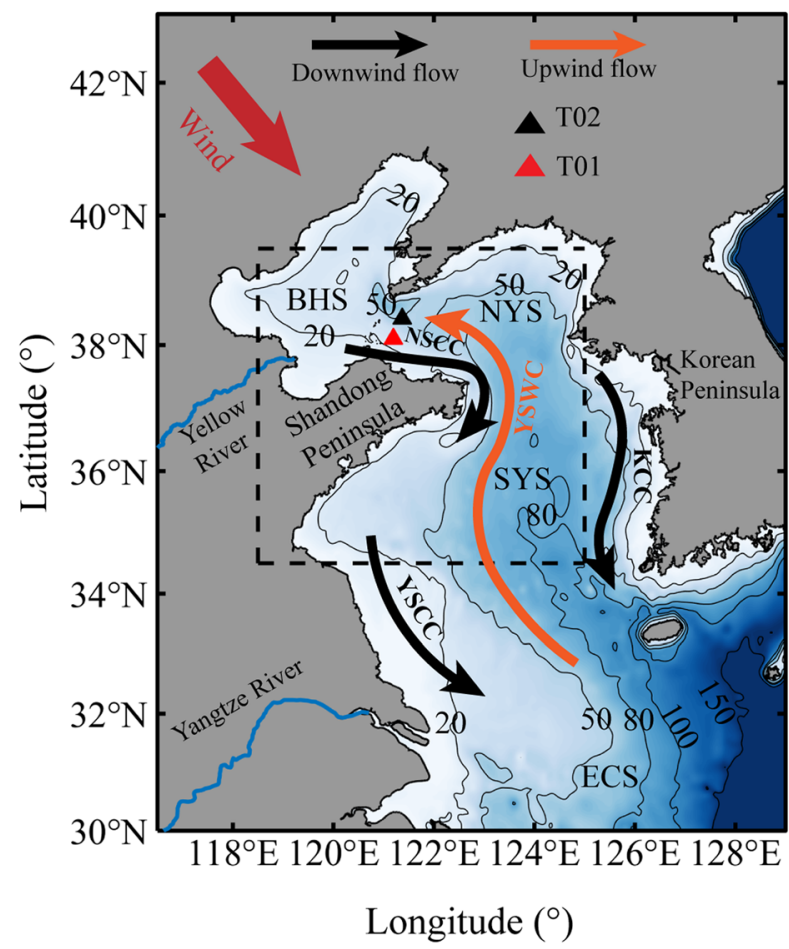

(b)
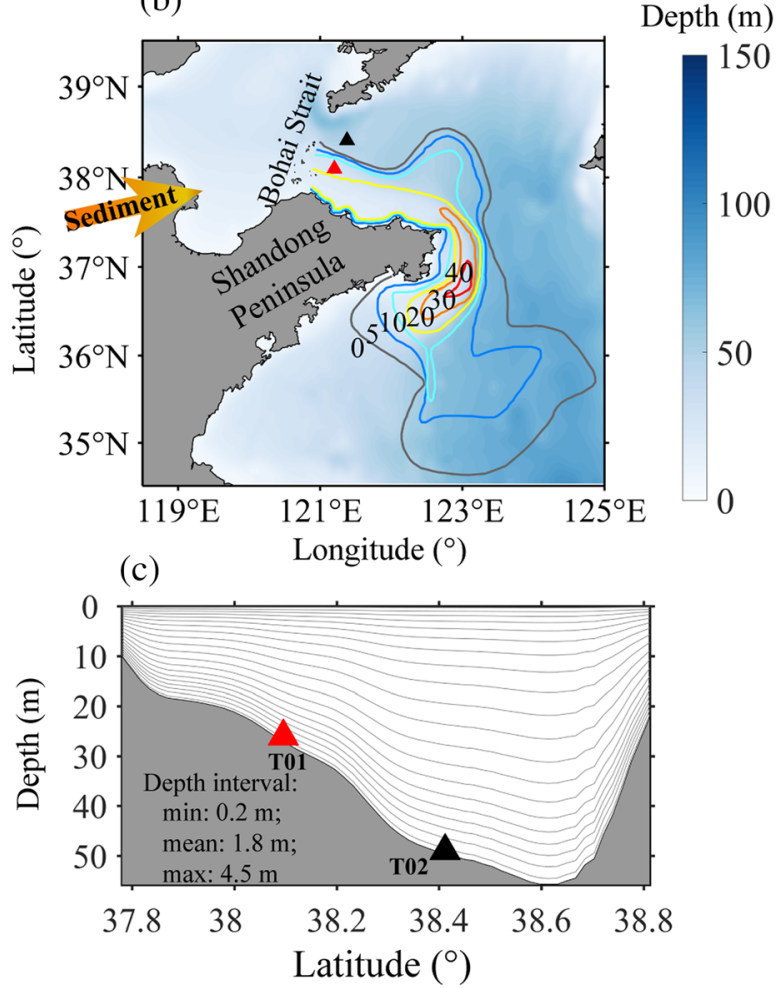

Figure 1. (a) Bottom topography of the Bohai Sea (BHS), Northern Yellow Sea (NYS), Southern Yellow Sea (SYS), and East China seas (ECS). The curved arrows are regional currents that can be grouped into two categories. Downwind flow: The Northern Shandong Peninsula Coastal Current (NSCC), the Yellow Sea Coastal Current (YSCC), and the Korea Coastal Current (KCC). Upwind flow: the Yellow Sea Warm Current (YSWC). The two observation platforms in the Bohai Strait are shown in two triangles. (b) The isopach map (unit: $\mathrm{m}$ ) of the mud clinoform from Yang and Liu (2007). (c) The terrain-following sigma layers (20 levels) in the Bohai Strait used in the model.

In this study, field measurements are combined with a 3D numerical model to provide detailed views of the exchange flow variations and sediment dynamics in the strait under a typical winter storm event. We first describe the study site and the regional setting in section 2. Configurations of field observation and numerical models are presented in section 3. In section 4, the barotropic ocean responses to the wind buildup and relaxation processes are discussed based on the daily averaged results of the model. Diagnostic analyses of the model momentum terms are presented in section 5 to discuss the dominant mechanism for sediment transport. The main conclusions are listed in section 6 .

\section{Study Site and Regional Setting}

Bohai Strait is a shallow, 100-km-wide passage that connects the Bohai Sea and Yellow Sea (Figure 1). Several small islands divide the strait into two parts, which are the shallow section in the south and a deeper section in the north, with typical water depths of 20-30 and 60-70 m, respectively. The Bohai Sea in the northwest of the strait is an enclosed shallow basin with relatively flat seafloor and an average water depth of $18 \mathrm{~m}$. Yellow River enters the Bohai Sea on the southwest side in the present days. The Yellow Sea, located between China and the Korea Peninsula, is characterized by a so-called "double shelf" topography. An elongated deep trough extends northward from the Southern Yellow Sea with a maximum water depth of more than $90 \mathrm{~m}$. There is an extended continental shelf with the isobaths roughly parallel to the coastline to the western side of the trough. The shelf on the Korea side is much steeper and dotted with several small islands (Figure 1a).

In winter, East Asian Monsoon dominates the synoptic variations of atmospheric forcing in the region. Strong northerly or northwesterly winds characterized by speed exceeding Beaufort scale $6(10.8-13.8 \mathrm{~m} /$ s) to $8(17.2-20.7 \mathrm{~m} / \mathrm{s})$ frequently occur over the Bohai Sea and Yellow Sea (Mo et al., 2016; Zhao \& 
Jiang, 2011). Under the prevailing northwesterly winds, shelf circulations of the Bohai Sea and the Yellow Sea are mainly composed of several along-shore downwind flows and a significant intrusion of upwind flow in the middle of the Yellow Sea (Figure 1a). The downwind Northern Shandong Peninsula Coastal Current (NSCC) originates in the Bohai Sea and enters the Northern Yellow Sea through the southern section of the Bohai Strait. In the Yellow Sea, both the Yellow Sea Coastal Current (YSCC) and Korea Coastal Current (KCC) flow southward along the Chinese and Korean coast, respectively (Naimie et al., 2001; Yuan \& Hsueh, 2010). The Yellow Sea Warm Current (YSWC), sandwiched between these two downwind flows, moves northward along the Yellow Sea Trough (deep water) with westward deviation tendency (Lin et al., 2011). Previous studies have shown that in winter, YSWC extends into the Bohai Sea through the deeper, northern channel of the Bohai Strait, while the eastward NSCC flows out through the shallow, southern section. Both long-term averaged current records in winter, and objective analysis of salinity fields reveal that outflows and inflows occurred respectively in the southern and northern sections of the strait (Zhang et al., 2018). This monthly or seasonally averaged pattern of the exchange flow in the Bohai Strait is generalized as "north-inflow and south-outflow" (Guan, 1994).

Furthermore, the rapid passage of storms can excite significant fluctuations of SSH in the Bohai Sea and the Yellow Sea, which produces CTWs (Ding et al., 2018; Hsueh \& Pang, 1989; Li \& Huang, 2019). The wind-driven CTWs theories have been applied to the Yellow Sea characterized by double-shelf topography (Hsueh \& Pang, 1989) and the East China Sea characterized by a broad continental shelf (Yin et al., 2013). The CTWs can be considered to represent a hybrid between shelf waves (barotropic Rossby waves) and Kelvin waves. The amplitude of Kelvin waves decays exponentially away from the shore, while the maximum amplitude of shelf waves is not at the shore but over the shelf with deeper water. On the shelf of the Yellow Sea, there are oppositely propagating shelf waves on the Chinese shelf and Korea shelf, respectively. Low sea level signals propagate southward along the isobaths on the Chinese shelf (western side of the Yellow Sea), while high sea level signals propagate northward along the isobaths on the Korea shelf (eastern side of the Yellow Sea). The amplitudes of two sets of shelf waves are confined to a different shelf, which can be distinguished by the counter direction movement. Previous works found that strong northerly winds can cause a rapid drawdown of SSH in the Bohai Sea, accompanied by the propagation of CTWs in the Yellow Sea (Jacobs et al., 1998). The propagation of CTWs not only has a remarkable influence on the strength of the YSWC (Ding et al., 2018; Hu et al., 2017; Qu et al., 2018) but also facilitates volume exchange through the Bohai Strait (Ding et al., 2019; Wan et al., 2014). However, the relative role of storms, CTWs, and their contributions to sediment transport processes through the strait are presently unclear.

\section{Methods}

\subsection{Field Observations}

We conducted a 3-week (18 December 2017 to 8 January 2018) hydrographic survey in the Bohai and the Yellow Sea. CTD casts were taken at 112 stations wrapping around the Shandong Peninsula. During the latter half of the cruise, a surface and a subsurface mooring were deployed respectively at site T01 (water depth: 29 m; record length: 6-13 January 2018) and T02 (water depth: $51 \mathrm{~m}$; record length: 2-13 January 2018) in the Bohai Strait (Figure 1). Each mooring was equipped with instrument arrays, including Seabird CTD sensors, RBR temperature, and salinity sensors, and RBR turbidity sensors measured time series of temperature, salinity, and turbidity throughout the water column. All the instruments on the moorings sampled at a cycle of $10 \mathrm{~s}$. A sediment trap with seven sampling bottles was equipped at the bottom of each mooring (about 5 $\mathrm{MAB}$, meters above the bed), to collect deposited particles at a cycle of 1 day. Next to each mooring was a watching ship as well as an instrumented tripod (at T01) or a bottom-mount platform (at T02) equipped with RDI $600 \mathrm{kHz}$ ADCPs, temperature, salinity, and turbidity sensors. The upward-looking ADCP transducers were mounted at 1.5 MAB on the T01 tripod, and $0.8 \mathrm{MAB}$ on the T02 bottom-mount platform. The vertical sampling interval of the currents was set to $0.75 \mathrm{~m}$, and the sampling cycle was $20 \mathrm{~min}$. The sampling time of each ping was $24 \mathrm{~s}$, and 50 pings were used to get the average current profiles. In addition, from 09:00 (6 January) to 10:00 (7 January), the watching ship carried out hourly sampling of water samples and particle size distribution by casting Niskin bottles and LISST-200X on the surface layer (1 $\mathrm{m}$ underwater), the middle layer ( 0.4 times of water depth), and the bottom layer (about $3 \mathrm{MAB}$ ). All water samples were filtered by pumping with the oven-dried double-layer membrane (mean pore size $0.45 \mu \mathrm{m}$ diameter) to get the SSC. The suspended sediment concentration profiles were estimated from the amplitude of the ADCP 
backscatter signal (Thorne \& Hurther, 2014) by correlating the backscatter intensity with the measured SSC obtained via pump samples. The correlation coefficients between the ADCP-estimated SSC and measured SSC are 0.73 in site T01 and 0.77 in site T02.

\subsection{Model Setup and Configurations}

The Coupled Ocean-Atmosphere-Wave-Sediment Transport Modeling System (COAWST) was utilized to reproduce the oceanographic circulation and sediment dynamics (Warner et al., 2010). COAWST is comprised of several model components that include Regional Ocean Modeling System (ROMS) hydrodynamic model (Shchepetkin \& McWilliams, 2005), Weather Research and Forecasting (WRF) model (Skamarock et al., 2005), Simulating Waves Nearshore (SWAN) wave model (Booij et al., 1999), and Community Sediment Transport Modeling Systems (CSTMS) sediment transport model (Warner et al., 2008). These models are coupled via the Model Coupling Toolkit (MCT, Larson et al., 2005), and different combinations of these models can generate various computational pathways to perform multiple capabilities. In this study, we deactivated the WRF model but coupled the ROMS, SWAN, and CSTMS models to focus on the sediment transport processes dominated by subtidal flow variation and wave-current interaction.

The ROMS model was used to simulate the characteristics and dynamics of shelf circulation in the Bohai Sea and the Yellow Sea. Eddy viscosities and diffusivities were calculated by Mellor-Yamada Level 2.5 Turbulence Closure (Mellor \& Yamada, 1982). The model grid domain extended meridionally from $30^{\circ} \mathrm{N}$ to $44^{\circ} \mathrm{N}$, zonally from $116^{\circ} \mathrm{E}$ to $128^{\circ} \mathrm{E}$, which covered the Bohai Sea and the Yellow Sea with about $2.5^{\prime} \times 2.5^{\prime}$ horizontal resolution. The water depth ranged from 5 to $135 \mathrm{~m}$ and vertically was discretized into 20 levels on stretched terrain-following sigma coordinate (Figure 1c). A higher resolution was established within the bottom and surface boundary layers by setting the surface control parameter to 4, and the bottom control parameter to 0.8 in the stretching function (Song \& Haidvogel, 1994). In order to capture ocean response to synoptic wind events, we used real-time atmosphere forces including surface winds, radiation (short wave and long wave), temperature, air pressure, air precipitation rate, and relative humidity. These atmospheric forces were obtained from the European Centre for Medium-Range Weather Forecasts (ECMWF) ERA-Interim data set with a 3-hr interval and $0.125^{\circ} \times 0.125^{\circ}$ horizontal resolution (Berrisford et al., 2009). The surface momentum flux, heat, and salt fluxes from the atmospheric conditions were calculated inside ROMS using a bulk flux formula (Fairall et al., 2003). At lateral (south and east) open boundaries, three-dimensional temperature, salinity, and subtidal current fields from the HYCOM + NCODA Global $1 / 12^{\circ}$ Analysis were extracted acting as daily exterior forcing with mixed radiation-nudging boundary condition (Marchesiello et al., 2001). As for tidal boundary conditions, eight principle tidal constituents $\mathrm{M}_{2}$, $\mathrm{S}_{2}, \mathrm{~N}_{2}, \mathrm{~K}_{2}, \mathrm{~K}_{1}, \mathrm{O}_{1}, \mathrm{P}_{1}$, and $\mathrm{Q}_{1}$ derived from the TPXO8 tidal model were prescribed along the eastern and southern boundaries (Egbert \& Erofeeva, 2002). Chapman boundary condition was used for surface elevation (Chapman, 1985). A Flather-type radiation condition (Flather, 1987) was applied to transfer momentum from 2D barotropic energy out of the model domain.

The SWAN model used the same geographical domain as ROMS and applied hourly time-series wind data from the NCEP Climate Forecast System Version 2 (CFSv2, spatial resolution $0.205^{\circ} \times 0.204^{\circ}$ ) to obtain realistic estimates of wave parameters. We used the CFSv2 winds to force the SWAN model and ERA-Interim winds to force the ROMS model because our early model tests showed that the wave fields were sensitive to the temporal resolution of wind fields, but the currents performed better using the higher spatial resolution winds from the ERA-Interim. The entire circular spectrum was equally divided into 36 directional bands, and the frequency domain was equally divided into 25 bins, ranging from 0.04 to $1 \mathrm{~Hz}$. The third-generation SWAN model was run in nonstationary mode with 20-min time steps, taking into account dissipation due to white capping, bottom friction, and wave breaking. During the coupling procedure, ROMS provided arrays of current velocity and water level to SWAN and the SWAN model transferred wave parameters such as significant wave height, wave period, wave propagation direction, energy dissipation, and wave-orbital velocity to the ROMS model. The data exchange time interval was $1 \mathrm{hr}$.

In the sediment model, the seabed was designed to have five layers that were initially each $1 \mathrm{~m}$ thick. We initialized seabed sediment arrays with three non-cohesive size classes (sand, silt, and clay) whose fractions were set to be vertically homogeneous but horizontally heterogeneous. The initial distributions of the three sediment classes in the Bohai Sea and the Yellow Sea (Figure 2) were based on published data in Li et al. (2014), Yuan et al. (2020) and Qin et al. (2018). The Yellow River discharge and riverine sediment were 

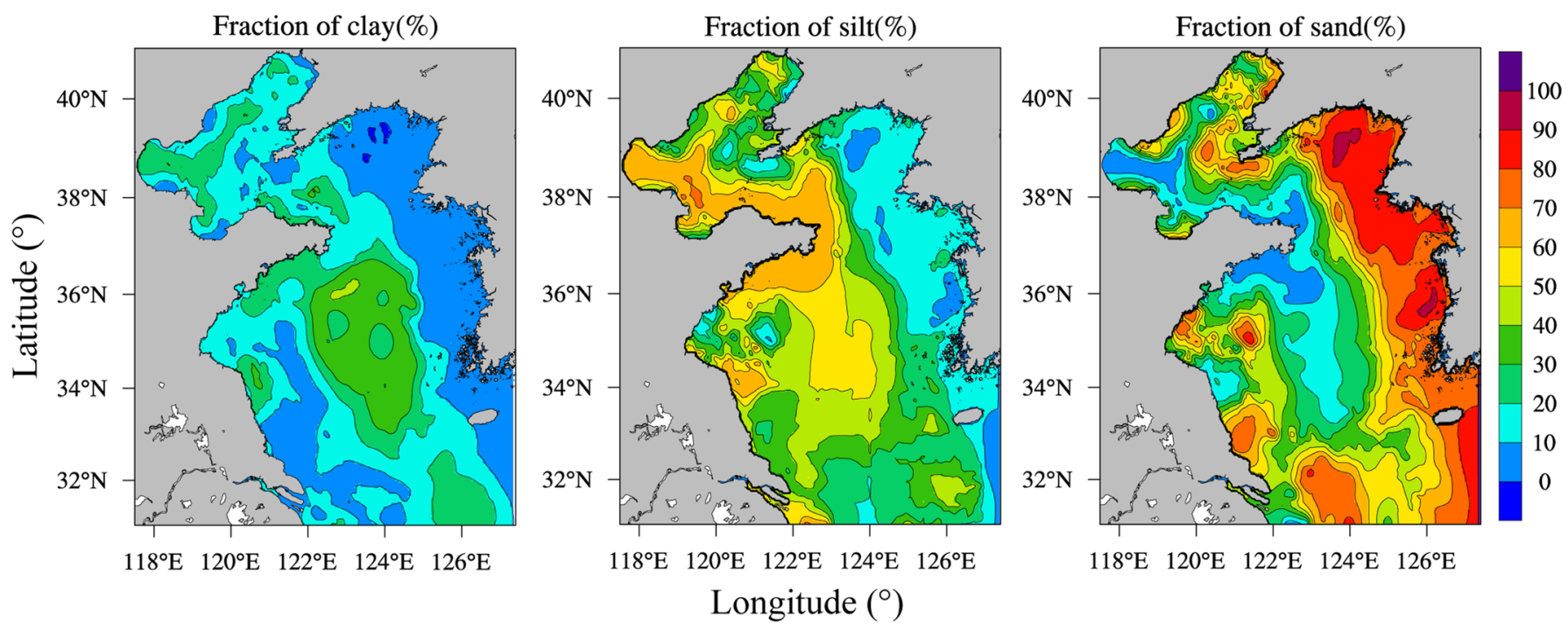

Figure 2. The spatial distribution of three sediment class fractions, based on data from Li et al. (2014) Yuan et al. (2020) and Qin et al. (2018).

based on monthly records from the Lijin hydrographic station located $\sim 100 \mathrm{~km}$ upstream of the river mouth. The fractions of sand, silt, and clay in the Yellow River were set to $10 \%, 70 \%$, and $20 \%$ respectively, following Wang et al. (2019). The bottom roughness lengths were mainly evaluated from sediment transport roughness and spatially varying mean grain diameter. The combined wave-current interaction algorithms of Madsen (1995) were implemented in the bottom boundary layer to calculate the enhanced shear stresses. Because this study mainly focused on successive erosion, advection, and deposition processes caused by winter storms, the sediment model considered only suspended load and bedload was neglected.

Due to the lack of measured values of sediment settling velocity, critical shear stress, and erosion rate, the sediment module was subjected to sensitivity experiments to find optimal choices. We set the sand composition to fine sand with a grain diameter of $0.125 \mathrm{~mm}$. The related settlement velocity and critical shear stress were calculated from Stokes settling equation and nondimensional Shields curve, respectively. For the bed erosion rate $\mathrm{E}_{0}$, other implementations of the ROMS sediment model have used values ranging from $10^{-6}$ to $10^{-3} \mathrm{~kg} / \mathrm{m}^{2} / \mathrm{s}$ (Xu et al., 2016). We set the value of $E_{0}$ to $2.5 \times 10^{-5} \mathrm{~kg} / \mathrm{m}^{2} / \mathrm{s}$ for all three sediment classes; this was the same order of magnitude as the value used by previous models of the Bohai Sea and Yellow Sea (Bian et al., 2013; Wang et al., 2019; Zeng et al., 2015). In these previous models, the grain diameters of clay and silt were usually set to 0.156 and $0.0039 \mathrm{~mm}$, respectively, and corresponding low values of setting velocities $w_{s}$ and critical shear stress $\tau_{c}$ were used. Considering that physical processes like flocculation and consolidation might occur in this cohesive sedimentary environment, sensitivity analyses were conducted to determine the adequate values of $w_{s}$ and $\tau_{c}$. We gradually increased the values of $w_{s}$ and $\tau_{c}$ of silt and clay to explore the SSC response and compared it to observed values in the sensitivity analyses (Figure 3 ).

As shown in Figure 3a, the ADCP-derived SSC showed two peaks of sediment concentration of about $50 \mathrm{mg} / \mathrm{L}$ during the observations at T01. The values of SSC dropped quickly after the peak for each event, indicating that the suspended particles settled quickly after the storm. However, in the model that used low $w_{s}$ and $\tau_{c}$, the simulated SSC was significantly higher than the observed values, and its temporal behavior differed from the observations. Observed turbidity data (TU) by RBR turbidity sensors at site T02 was converted to SSC, using the calibration formula obtained from pumping filtration: $\mathrm{SSC}=1.5254 \times \mathrm{TU}-1.5066\left(R^{2}=0.74\right)$. The observed SSC at $28 \mathrm{MAB}$ at site T02 mainly varied with the tidal currents, ranging from 5 to $15 \mathrm{mg} / \mathrm{L}$ (Figure $3 \mathrm{~b}$ ). When the model used low values of $w_{s}$ and $\tau_{c}$, it calculated slow particle deposition and large erosion flux. Using an increased $\tau_{c}$ decreased the simulated SSC significantly; As $w_{S}$ increased, the modeled SSC showed the variability of sediment concentration in response to current fluctuations with different velocity amplitudes that were in better agreement with the temporal patterns of the measured SSC. Based on these results, the settling velocity was set to $1 \mathrm{~mm} / \mathrm{s}$ for silt and $0.5 \mathrm{~mm} / \mathrm{s}$ for clay, and critical shear stress was 
(a)

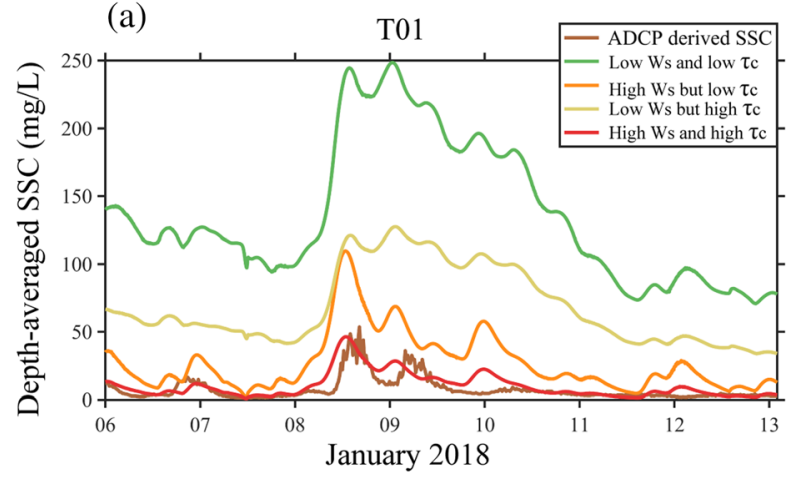

(b)

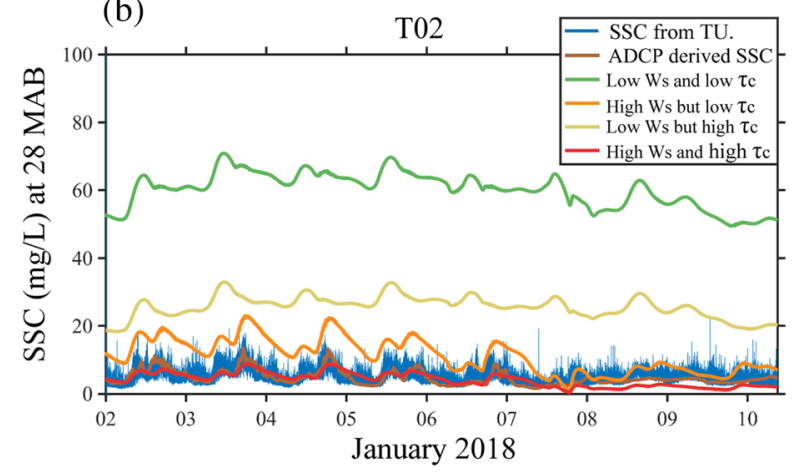

Figure 3. Sensitivity analyses to sediment parameters. (a) Depth-averaged SSC (mg/L) from model and ADCP at site T01. (b) Simulated and observed SSC (mg/L) at $28 \mathrm{MAB}$ at site T02. Low setting velocity: $w_{s}=0.05 \mathrm{~mm} / \mathrm{s}$ for clay and $0.15 \mathrm{~mm} / \mathrm{s}$ for silt. High setting velocity: $w_{s}=0.5 \mathrm{~mm} / \mathrm{s}$ for clay and $1 \mathrm{~mm} / \mathrm{s}$ for silt. Low critical shear stress: $\tau_{c}=0.022 \mathrm{~N} / \mathrm{m}^{2}$ for clay and $0.038 \mathrm{~N} / \mathrm{m}^{2}$ for silt. High critical shear stress: $\tau_{c}=0.05 \mathrm{~N} / \mathrm{m}^{2}$ for clay and $0.1 \mathrm{~N} / \mathrm{m}^{2}$ for silt.

set to $0.1 \mathrm{~N} / \mathrm{m}^{2}$ for silt and $0.05 \mathrm{~N} / \mathrm{m}^{2}$ for clay (Table 1), which were consistent with the range of values that have been reported for mud (Whitehouse et al., 2000).

The full simulation model was initialized on the first day of January 2016 using temperature, salinity, current fields interpolated from the HYCOM model. Then, the model ran through the whole years of 2016, 2017, and the first 3 months of the year 2018, by using the previously introduced dynamic configurations. In addition, four numerical experiments were designed to investigate the mechanisms that control the exchange flow variations and SSF through the Bohai Strait in winter. The four reference model experiments were run from 1 December 2017 to 1 March 2018, with the same configurations but respectively having the wind, tide, or wave forcing turned on and off (Table 1). It should be noted that turning off the wind field here referred to turning off both the wind fields and the bulk flux calculation in the ROMS model (EXP1 and EXP3), in particular, it did not affect the wave model in EXP3. The verified full simulation model provided the same initial condition for the four shorter numerical experiments.

\section{Results}

\subsection{Observation Results and Model Validation}

The CTD casts data provided the distribution of water temperature and salinity. These snapshots of measured sea conditions were used to validate the thermohaline simulation. The spatial distribution of temperature and salinity between CTD casts data and simulations are plotted in Figure 4. The model results

Table 1

Experiment Configurations and Parameters in the Sediment Model

\begin{tabular}{lllll}
\hline ROMS model & Wind & \multicolumn{1}{l}{ Tide } & Wave (couple with SWAN) \\
\hline Full simulation & Yes & Yes & Yes & \\
EXP1 & No & Yes & No & \\
EXP2 & Yes & Yes & No & \\
EXP3 & No & Yes & Yes & \\
EXP4 & Yes & No & Yes & \\
\hline Sediment model parameters & Sand & \multicolumn{2}{c}{ Silt } & Clay \\
\hline Grain diameter $(\mathrm{mm})$ & 0.125 & 0.016 & 0.0039 \\
Settling velocity $w_{s}\left(\mathrm{~mm}^{2} / \mathrm{s}\right)$ & 8.7 & 1 & 0.5 \\
Critical shear $\tau_{c}\left(\mathrm{~N} / \mathrm{m}^{2}\right)$ & 0.14 & 0.1 & 0.05 \\
Erosion rate $\mathrm{E}_{0}\left(\mathrm{~kg} / \mathrm{m}^{2} / \mathrm{s}\right)$ & $2.5 \times 10^{-5}$ & $2.5 \times 10^{-5}$ & $2.5 \times 10^{-5}$ \\
Density $\left(\mathrm{kg} / \mathrm{m}^{3}\right)$ & 2,650 & 2,650 & 2,650 \\
Porosity & 0.3 & 0.3 & 0.3 \\
& & & & \\
\hline
\end{tabular}

for the time that corresponded to the cruise survey period (from 18 December 2017 to 8 January 2018) were averaged. Both the observation and the models showed a warm tongue along the western side of the Yellow Sea Trough and extending up to the Bohai Strait, which indicated the northwestward intrusion of YSWC. Simulated salinities were in the same range of the CTD cast data, and salinities increased southward and seaward both in the surface and bottom waters. The discrepancy between modeled and observed salinity may be related to the inaccuracy of evaporation and precipitation data, and the model's use of monthly averaged river discharge data. The model also showed good agreement with the observations in that it captured the minimal differences in the temperature and salinity between the surface and bottom layers, indicating that the Bohai Sea and the Yellow Sea were well mixed in winter.

The in situ platform observations and model simulation captured a strong winter storm that began on 8 January 2018. Maximum wind 


\section{Temperature}
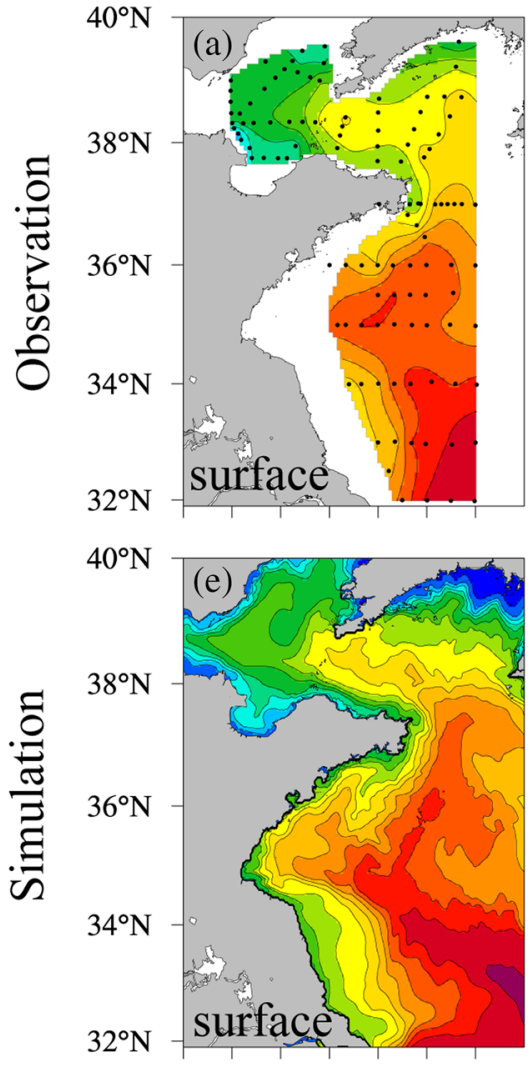

$118^{\circ} \mathrm{E} \quad 120^{\circ} \mathrm{E} \quad 122^{\circ} \mathrm{E} \quad 124^{\circ} \mathrm{E}$
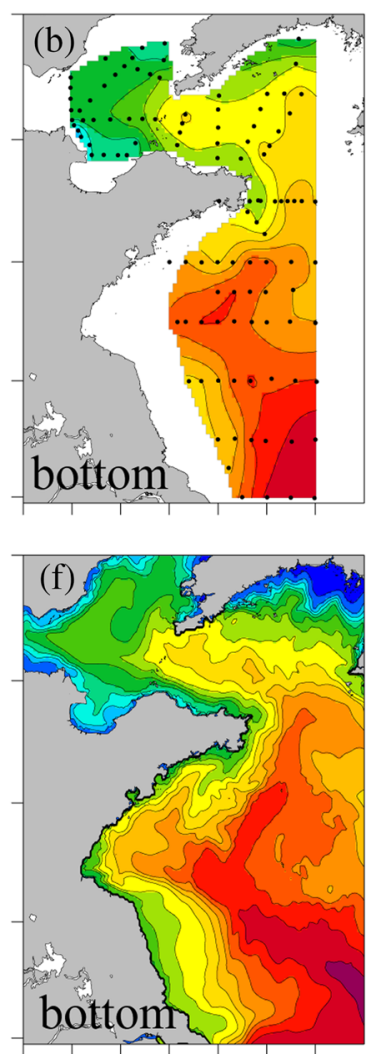

$118^{\circ} \mathrm{E} \quad 120^{\circ} \mathrm{E} \quad 122^{\circ} \mathrm{E} \quad 124^{\circ} \mathrm{E}$
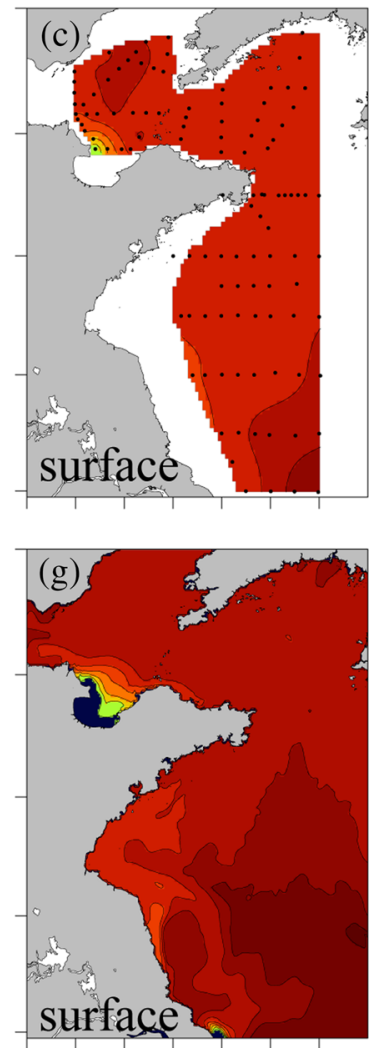

$118^{\circ} \mathrm{E} \quad 120^{\circ} \mathrm{E} \quad 122^{\circ} \mathrm{E} \quad 124^{\circ} \mathrm{E}$
Salinity
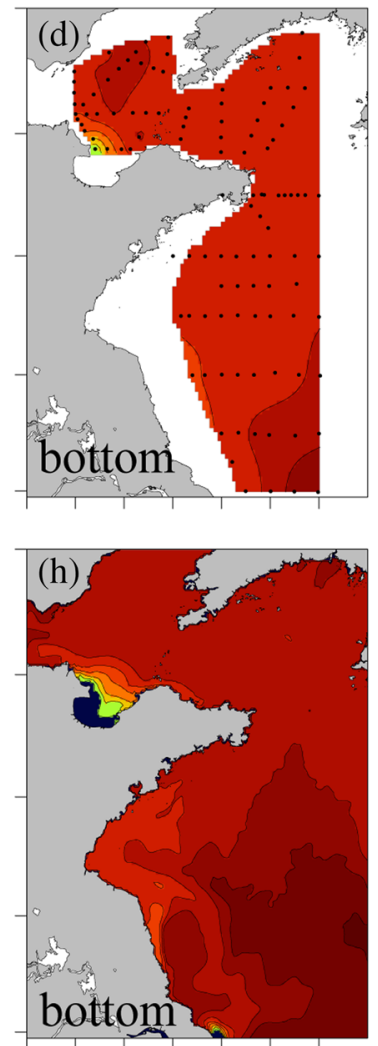

$118^{\circ} \mathrm{E} \quad 120^{\circ} \mathrm{E} \quad 122^{\circ} \mathrm{E} \quad 124^{\circ} \mathrm{E}$
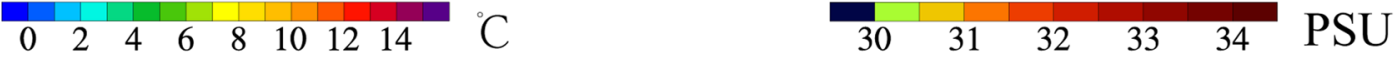

Figure 4. Observed (a-d) and modeled (e-h) temperature $\left({ }^{\circ} \mathrm{C}\right)$ and salinity (PSU) distribution at surface and bottom. The black dots in panels (a)-(d) indicate the CTD stations.

speed reached $15 \mathrm{~m} / \mathrm{s}$ in the strait and $17 \mathrm{~m} / \mathrm{s}$ in the Yellow Sea, with winds primarily from the northwest to southeast. Sustained winds of $\sim 10 \mathrm{~m} / \mathrm{s}$ lasted for 2 days before gradually subsiding on 11-13 January (Figure 5). During the relaxation of the storm on 11 January, the wind direction turned from the northwest, to from the west, and then from the southwest during the following 2 days. Thus, we designate 8-10 January as the buildup phase of the northerly wind storm, while 11-13 January as the relaxation period. The significant wave height $(H s)$ was generally low $(<1 \mathrm{~m})$ in the coastal region and gradually increased in the seaward direction. In the storm buildup phase, surface waves with $H s>2$ m were mainly found in the central region of the Bohai Sea, the Bohai Strait, and the deep-water region of the Yellow Sea (Figure 5). As the northerly winds weakened and rotated to be from the southwestward direction, the significant wave height was greatly reduced. The time-series variations of Hs reproduced by model well matched the in-situ records from the upward-looking ADCPs at sites T01 and T02 (Figures 6a and 6b). Prior to the onset of the storm (7 January), results from both the simulations and measurements showed that the $H s$ gradually decreased to be near zero, primarily because of the calm wind conditions. A marked increase in $H s$ occurred on 8 January as the winter storm arrived. The significant wave heights at the two sites were generally greater than $2 \mathrm{~m}$ during the northerly wind buildup phase (8-10 January). The timing of the peak of the storm was spatially variable, but at the peak of the storm as observed in Bohai Strait, the measured maximum $H s$ at sites T01 and T02 were 3.44 and $2.88 \mathrm{~m}$, respectively. The model performance was assessed in terms of the root mean square error (RMSE), and model performance skill proposed by Willmott (1981), they are defined as 
(a) 08 January 2018

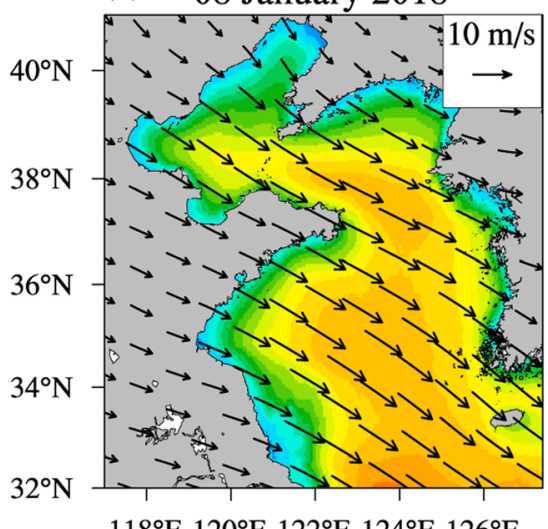

$118^{\circ} \mathrm{E} 120^{\circ} \mathrm{E} 122^{\circ} \mathrm{E} 124^{\circ} \mathrm{E} 126^{\circ} \mathrm{E}$

(d) 11 January 2018

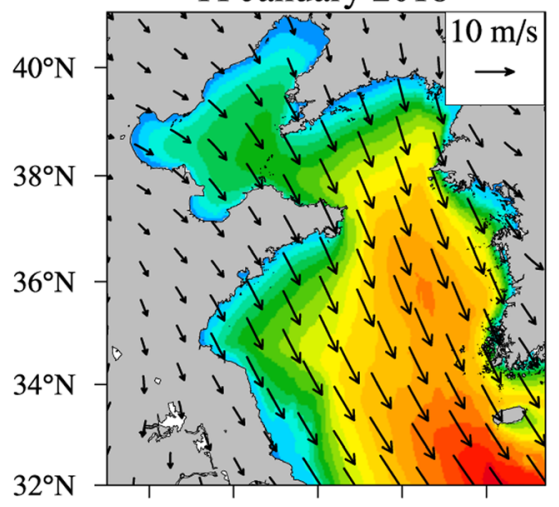

$118^{\circ} \mathrm{E} 120^{\circ} \mathrm{E} 122^{\circ} \mathrm{E} 124^{\circ} \mathrm{E} 126^{\circ} \mathrm{E}$ (b) 09 January 2018

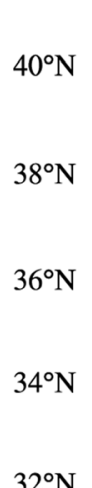

$32^{\circ} \mathrm{N}$

$118^{\circ} \mathrm{E} 120^{\circ} \mathrm{E} 122^{\circ} \mathrm{E} 124^{\circ} \mathrm{E} 126^{\circ} \mathrm{E}$

(e) 12 January 2018

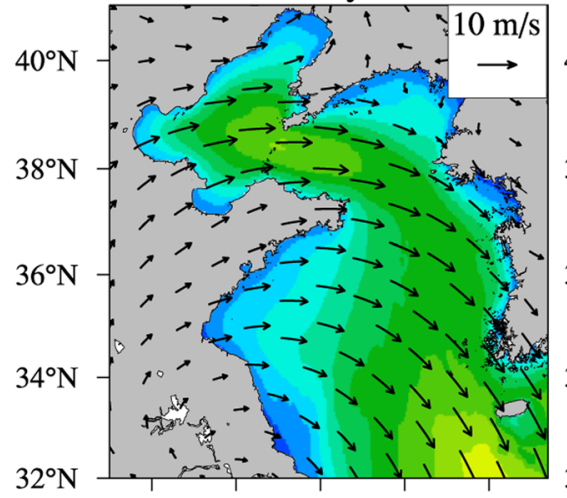

$118^{\circ} \mathrm{E} 120^{\circ} \mathrm{E} 122^{\circ} \mathrm{E} 124^{\circ} \mathrm{E} 126^{\circ} \mathrm{E}$ (c) 10 January 2018

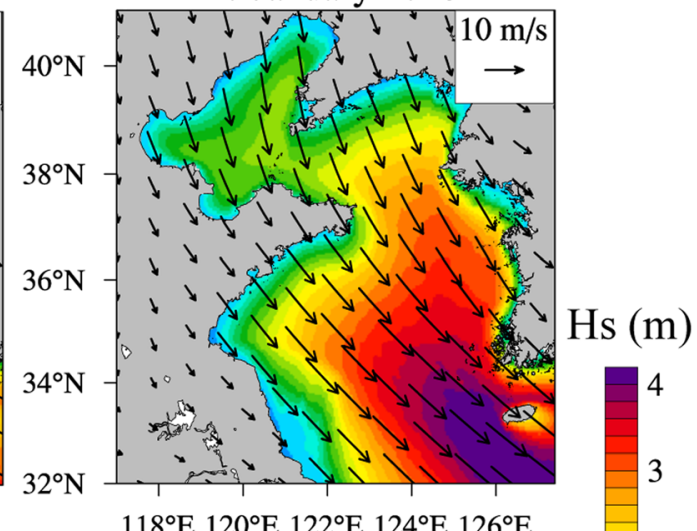

$120^{\circ} \mathrm{E} 122^{\circ} \mathrm{E} 124^{\circ} \mathrm{E} 126^{\circ} \mathrm{E}$

(f) 13 January 2018

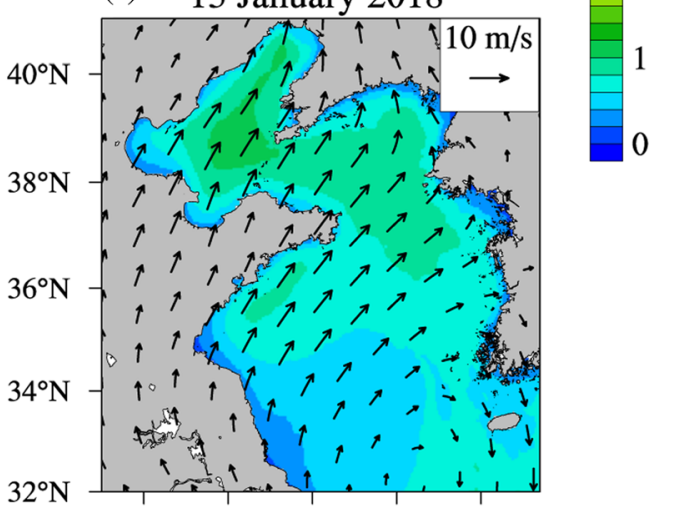

$118^{\circ} \mathrm{E} 120^{\circ} \mathrm{E} 122^{\circ} \mathrm{E} 124^{\circ} \mathrm{E} 126^{\circ} \mathrm{E}$

Figure 5. Daily averaged surface wind vectors (data from ERA-Interim) overlaid with the simulated significant wave height (m) on the (a-c) storm buildup phase and (d-f) storm relaxation phase.

$$
\begin{gathered}
\text { RMSE }=\left[\frac{1}{N} \sum_{n=1}^{N}\left(O_{n}-M_{n}\right)^{2}\right]^{1 / 2}, \\
\text { Skill }=1-\frac{\sum_{n=1}^{N}\left|M_{n}-O_{n}\right|^{2}}{\sum_{n=1}^{N}\left(\left|M_{n}-\overline{O_{n}}\right|+\left|O_{n}-\overline{O_{n}}\right|\right)^{2}},
\end{gathered}
$$

where $O_{n}$ are observations, $M_{n}$ are the model results at the same location and times, $N$ is the total number of observations, and the overbar represents the mean value of the data. For $H s$, the model performance skills were more than 0.93 (skill $=1$ means perfect agreement) and the root mean square errors (RMSE) were less than $0.25 \mathrm{~m}$, both suggesting that the model was able to capture the wave characteristics both in energetic or calm wind conditions.

The semi-diurnal M2 tidal currents in the Bohai Strait are the most predominant tidal constitutes. Since our focus is primarily on the water and sediment exchange through the strait, only the comparison of currents in the east-west direction (dominant component of tidal and subtidal currents) are shown. The model simulations precisely reconstructed the currents and sea level in both magnitude and phase (Figures 6c-6f). Measurements at sites T01 and T02 showed the transition of decreasing velocity magnitude and tidal sea level from spring tide to neap tide. The simulated and observed velocities show very similar variations of amplitude both before and during the storm buildup (Figures $6 \mathrm{e}$ and $6 \mathrm{f}$ ). The daily maximum magnitudes of depth-averaged velocities decreased from $0.75 \mathrm{~m} / \mathrm{s}$ on 6 January to $0.4 \mathrm{~m} / \mathrm{s}$ on 10 January at site T01, while at site T02, the daily maximum depth-averaged velocities were observed to reach $0.9 \mathrm{~m} / \mathrm{s}$ on 4 January and gradually decreased to $0.35 \mathrm{~m} / \mathrm{s}$ on 10 January. The model performance skills between the simulated and 
(a)

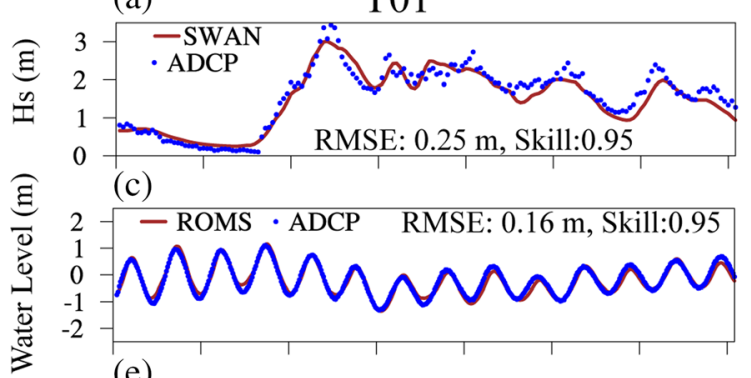

(e)

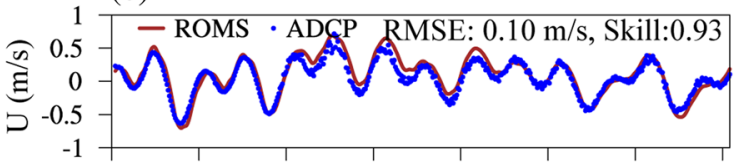

(g) ADCP derived SSC profile

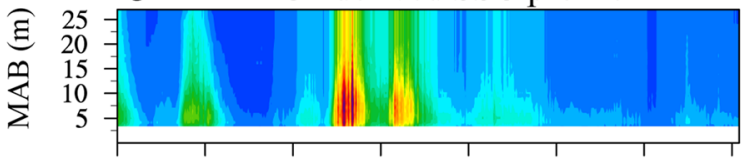

(i)

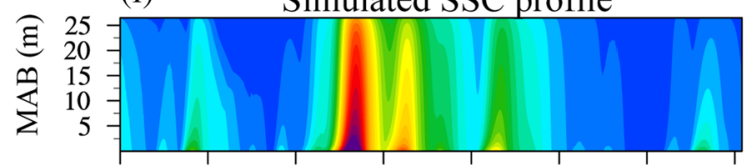

(k)

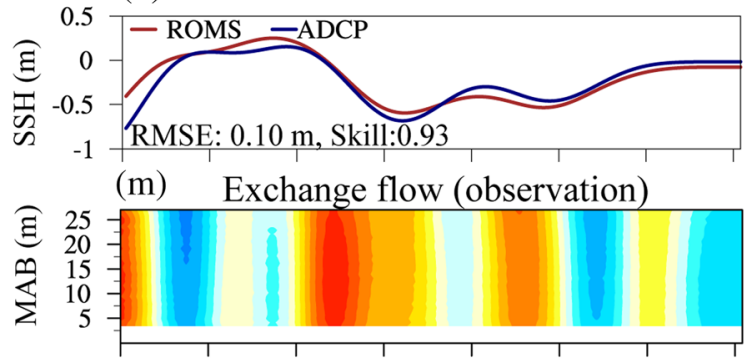

(o) Exchange flow (simulation)

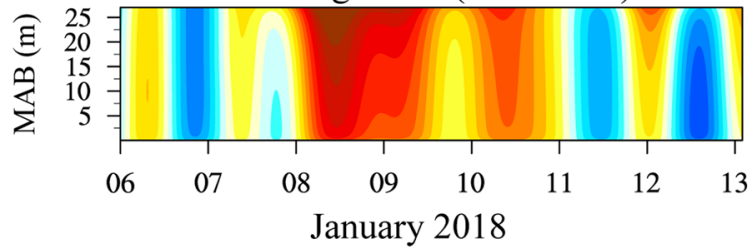

(b) T02

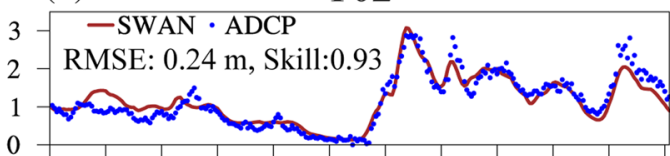

(d)

$2-$ - ROMS • ADCP RMSE: 0.10 m, Skill:0.95

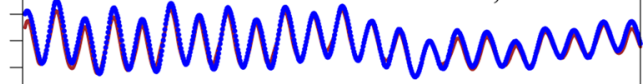

(f)

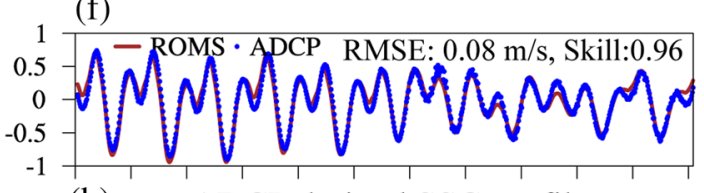

(h) ADCP derived SSC profile

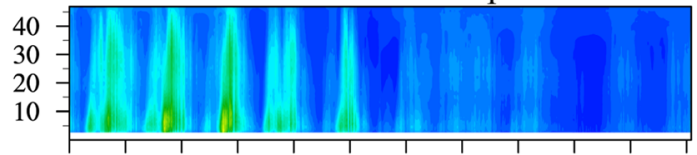

$\mathrm{mg} / \mathrm{L}$

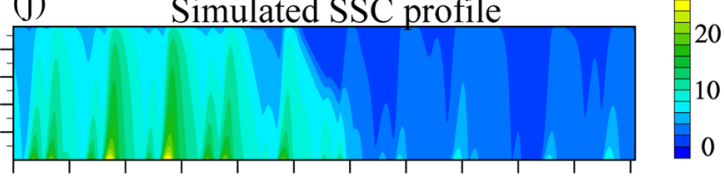

(1)
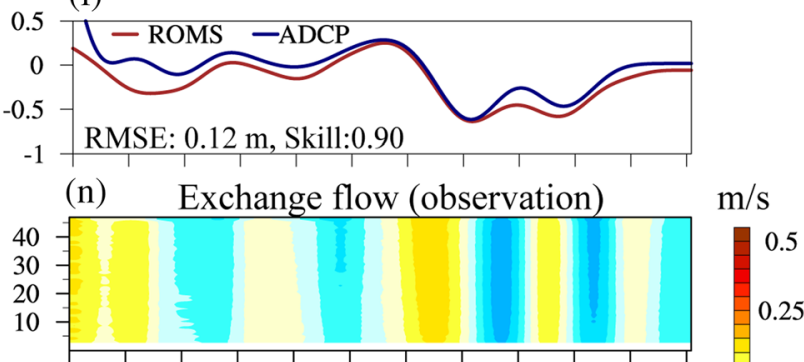

(p) Exchange flow (simulation)

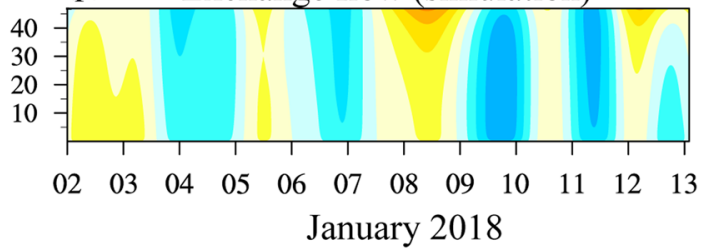

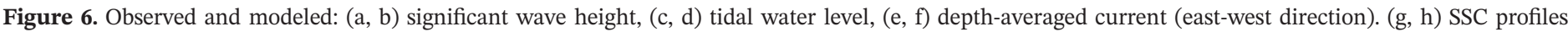

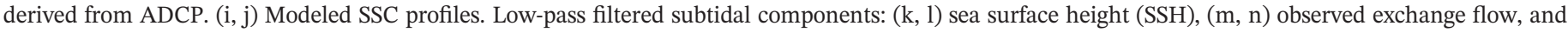

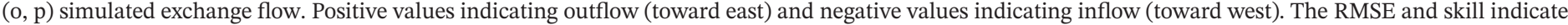
root mean square error, and model performance skill, respectively.

observed time series of depth-averaged currents were more than 0.90 , and the root mean square errors (RMSE) were less than $0.10 \mathrm{~m} / \mathrm{s}$.

The simulated SSC profiles by the numerical model matched well, in both magnitude and trend, with the ADCP-derived SSC profiles (Figures $6 \mathrm{~g}$-6j). At the onset of the storm (8 January), a marked increase of SSC occurred at the shallow-water site T01, most likely due to wave-induced resuspension as currents were moderately reduced. Both observation and model results show that the maximum SSC at site T01 could reach $50 \mathrm{mg} / \mathrm{L}$ (Figures $6 \mathrm{~g}$ and $6 \mathrm{i}$ ). In contrast, the SSC in the deep-channel site T02 primarily varied with the magnitude of tidal currents, with higher concentrations $(>10 \mathrm{mg} / \mathrm{L})$ during the spring tide (1-7 
January) and much smaller concentrations ( $<10 \mathrm{mg} / \mathrm{L}$ ) during neap tide (8-13 January). Wave effects from the storm had very limited influence on the sediment resuspension at the deep-channel site T02. Therefore, it can be inferred that, at the southern, shallow portion of the strait, the sediment resuspension is very active and dominated by both tidal currents and wave actions. At the northern deep channel, sediment resuspension becomes less active and the sediment distribution is modulated by tidal signals. The overall agreement between the COAWST model results and observations indicates that the models applied here well reproduce the hydrodynamic and sediment dynamic characteristics in the Bohai Strait.

\subsection{Exchange Flow Variations Due to the Arrival of Winter Storms}

A low-pass filter with a frequency cut-off of $1 / 30 \mathrm{hr}$ was applied to the observed and modeled tidal water level and current data to remove all signals in the semi-diurnal, diurnal frequency bands, or higher frequencies, but preserve subtidal components (Figures 6k-6p). Both the simulated exchange flow and SSH shows a good agreement with the measurements in magnitude and trend. The Willmott skill scores between the modeled and observed depth-averaged exchange flows were more than 0.8 at the two sites, and the RMSEs were less than $0.08 \mathrm{~m} / \mathrm{s}$ (not shown in figures). The exchange flows showed barotropic features lacking vertical stratification. The exchange flows fluctuate at low frequency, but their directions at the two sites were at times out of phase, that is, the flows at the two sites were sometimes in opposite directions. This phenomenon was particularly more noticeable during storms. For instance, when the northerly winds reached their peak (nearly $15 \mathrm{~m} / \mathrm{s}$ ) on 8 January, the outflow in the shallow-water site T01 intensified to the peak value of about $0.3 \mathrm{~m} / \mathrm{s}$, and the outflow lasted about 3 days from 8 to 10 January. At the same time, the flow in the northern site T02 showed an outflow on 8 January but reversed to a steady inflow on 9 January. With the relaxation of the northerly wind on 11 January, the subtidal flows at both sites across the strait became inflows. In summary, during the storm buildup and relaxation periods, the exchange flow patterns in the strait mainly presented as three phases: strait-wide outflow, north-inflow and south-outflow, and strait-wide inflow.

Empirical Orthogonal Function (EOF) analysis (Thomson \& Emery, 2014) was used to illustrate the spatial patterns and temporal variations of the exchange flow through the Bohai Strait in winter (December 2017February 2018, 90 days). The exchange flows across the strait were composed of EOF maps and corresponding principal components (PCs) time series. For comparison, each PC time series was normalized to span the range -1 to 1 . The first two-mode maps (EOF1 and EOF2) and their corresponding PCs are shown in Figures 7a, 7b, 7e, and 7f. The exchange flow across the Bohai Strait was depth averaged in the water column to provide a 2D perspective (Figure $7 \mathrm{~g}$ ). Positive values of the time series PC1 indicated outflow in the EOF1 map, while negative values represented inflow. The leading EOF1 map (explaining $78 \%$ of the variance) represented strait-wide nearly equal inflow and outflow (i.e., around Day 25). Frequency spectrum analysis of the time series PC1 showed that the synoptic current fluctuations of the leading mode (EOF1) in the Bohai Strait had a period of about 2-3 days (Figure 7c). The time series of SSH difference between site T01 and site T02 was in the range from -0.1 to $0.1 \mathrm{~m}$, which exhibited fluctuation behavior as well as a remarkably well correlation with the PC1 time series (Figure 7e). This result indicated that the synoptic current fluctuations may be determined by the pressure gradient force in north-south direction caused by the SSH difference of the Bohai Strait. Moreover, the second mode (EOF2) characterizes the times that inflow and outflow coexist in the strait (Figure 7b). Positive values of the time series PC2 indicated north-inflow and south-outflow patterns in the EOF2 map, while negative values represented north-outflow and south-inflow patterns. The corresponding principal component of the second mode (PC2) displayed different characteristics than PC1. The magnitude of peak values of the PC2 are much higher than its trough values, especially during the in situ observation period. This indicates that in map EOF2, the situation that outflow is on the southern side and inflow is on the northern side plays a dominant role, but the opposite pattern rarely occurs. Frequency spectrum analysis showed that the time series PC2 has no obvious periodicity (Figure 7c).

\subsection{Sediment Flux and Fate Through the Bohai Strait}

Figure 7h plots the time series of the depth-averaged SSC along the cross section of the strait (represented by the latitude in the $y$-axis). It shows that the depth-averaged SSC varied with tides (diurnal or semi-diurnal) and the fortnightly spring-neap cycle, but the most profound variations were at the synoptic time scale (a few days) in the shallow waters of the strait during strong northerly wind events. During the strong northerly wind event (Day 40, neap tide condition), the magnitude of the suspended concentration increased by 
(a) Mode 1: 78\%

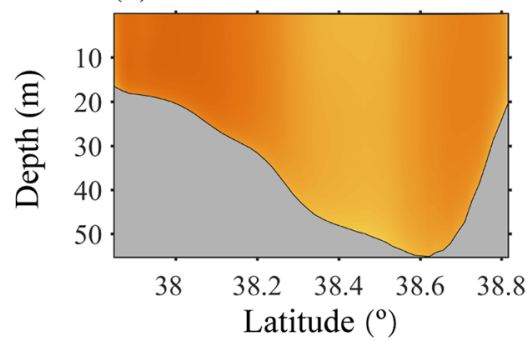

(b) Mode 2: 18\%

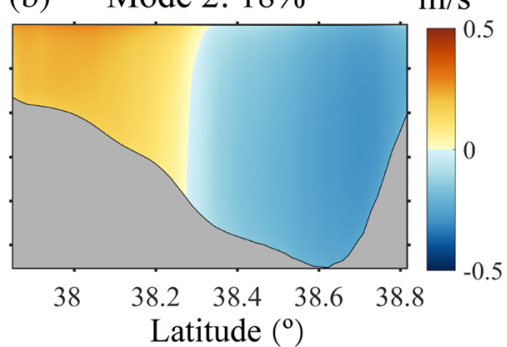

(c) Power spectral density

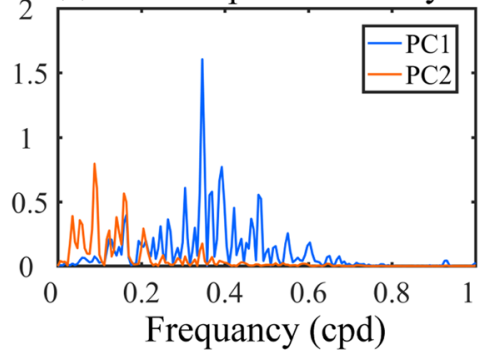

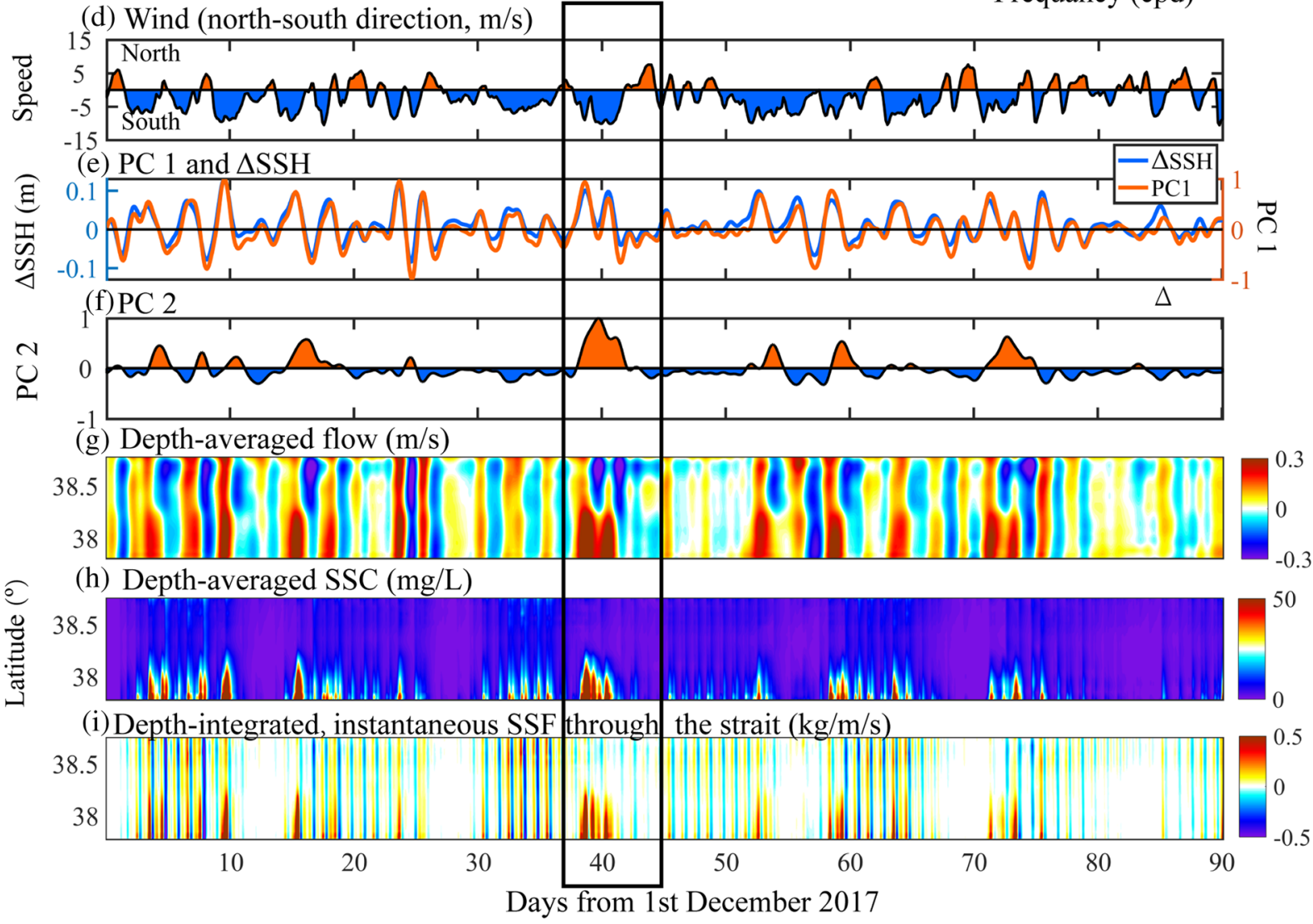

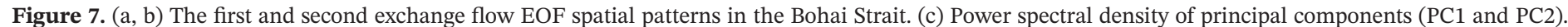

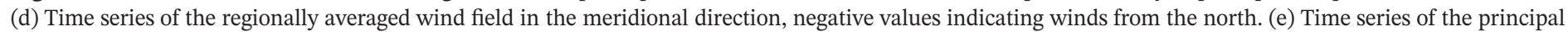
components (PCs) associated with the first EOF and the difference of SSH between sites T01 and T01. (f) Time series of the principal components (PCs)

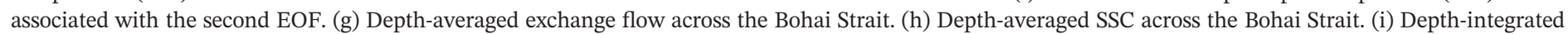

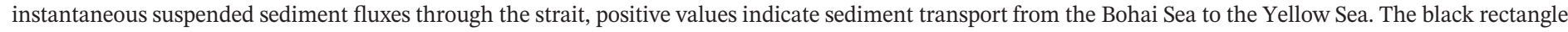
represents the storm event of this study.

fivefold (from $10 \mathrm{mg} / \mathrm{L}$ to more than $50 \mathrm{mg} / \mathrm{L}$ ). This SSC increase, however, was limited to the southern side of the strait, a phenomenon that undoubtedly influences the horizontal distribution of suspended sediments across the strait and sediment flux through the strait.

The instantaneous, through-strait, depth-integrated SSF was computed using the modeled velocity and SSC at each grid points along a cross-strait transect (Figure 7i):

$$
S S F=\sum_{i=1}^{N} \operatorname{ssc} h_{i}(u \cos \theta-v \sin \theta)
$$

where $u$ and $v$ are the eastward and northward components of the current velocity, $\theta$ is the angle between 


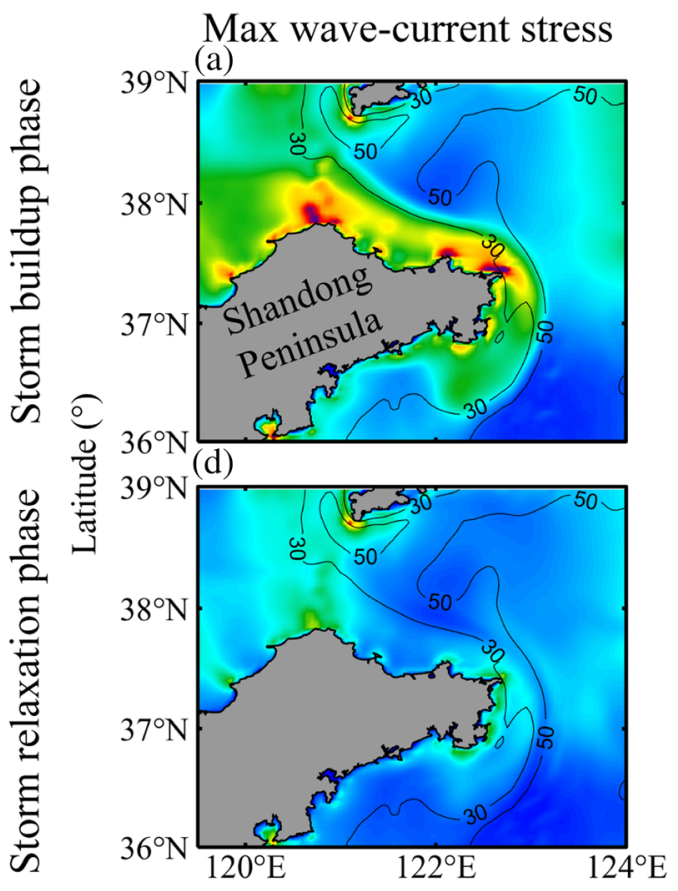

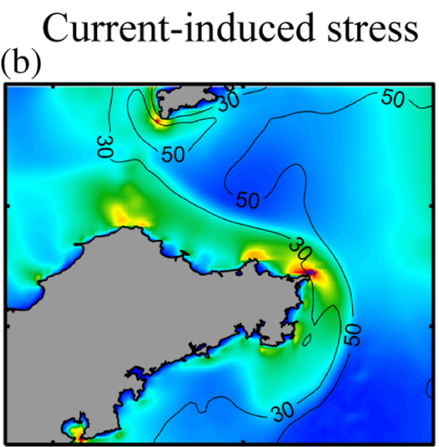

(e)

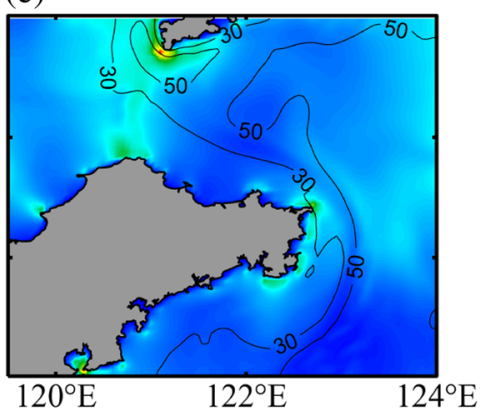

Longitude $\left(^{\circ}\right)$
Wave-induced stress

(c)

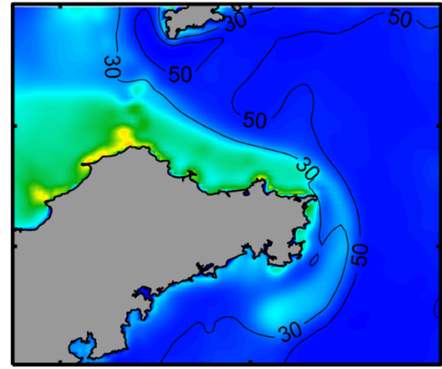

(f)

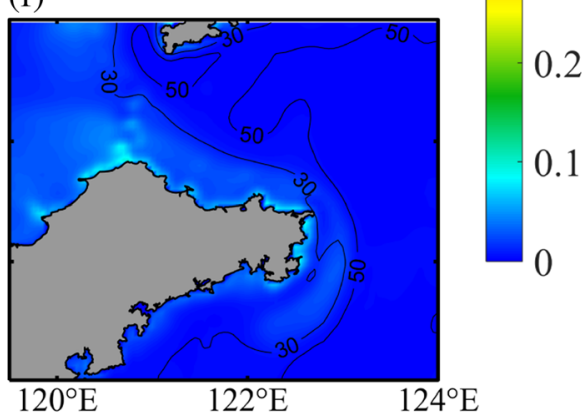

0.3

2

0.4

\section{.}

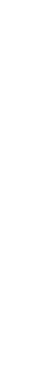

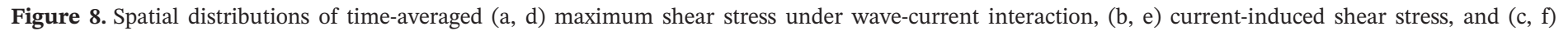
wave-induced shear stress, over 3 days in storm buildup phase (a- c) and storm relaxation phase (d-f).

the strait transect line and north, and $h_{i}$ is the thickness of water layer $i$ (from 1 to $N=20$ ). The instantaneous SSF was generally aligned with the magnitude and direction of tidal currents (Figure 7i). However, the peak of the SSF was not aligned with the periodic variation of the tidal current. Instead, it was more consistent with the peaks of the SSC in Figure 7h, suggesting a significant contribution from storm-induced resuspension. During winter storms from the north, both SSCs and exchange flow velocities were enhanced. This had the effect that the export of suspended sediment was generally larger than import, that is, net SSF occurred from the Bohai Sea to the Yellow Sea (Figure 7i). Next, we use the simulation results to explain in detail the sediment dynamic processes associated with shear stress, SSC and SSF variations.

The sediment model calculated the current-induced shear stress, wave-induced shear stress, and the maximum shear stress caused by wave-current interaction respectively at each time step ( $5 \mathrm{~min}$ ). The shear stress fields were averaged over 3-day periods to represent the storm buildup phase (8-10 January), and the storm relaxation phase (11-13 January). During the buildup phase, the high-value areas of the maximum shear force caused by wave-current interactions were mainly located on the southern side of the Bohai Strait and the shallow-water (less than $30 \mathrm{~m}$ ) region of the Shandong Peninsula. The horizontal distribution of current-induced and wave-induced shear stresses had comparable distribution ranges and magnitudes in the shallow-water region (Figures $8 \mathrm{~b}$ and $8 \mathrm{c}$ ). The locus of peak shear stress, and the presence of easily erodible, fine-grained sediment in the southern Bohai Strait (see Figure 2) explain the sharp increase of SSC there. In the deep channel on the northern side of the strait, the wave-induced shear stresses are negligible when compared to the current-induced shear stress (Figures $8 \mathrm{~b}$ and 8c). After the northerly wind weakened and the wind direction reversed, the wave-induced shear stress markedly decreased (Figure 8f). Notably, the current-induced shear stress also decreased (Figure 8e) particularly on the southern side of the Bohai Strait and along the coast of the Shandong Peninsula suggesting the important contribution of wind-driven currents during storms over these shallow-water regions.

Figure 9 showed the model results of the spatial distributions of depth-averaged SSC and depth-integrated sediment flux vectors. As the northerly wind strengthened on 8 January 2018, a marked increase of SSC 


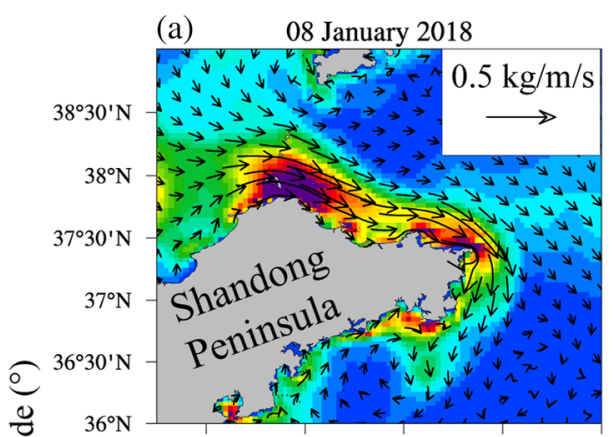

(d) 11 January 2018

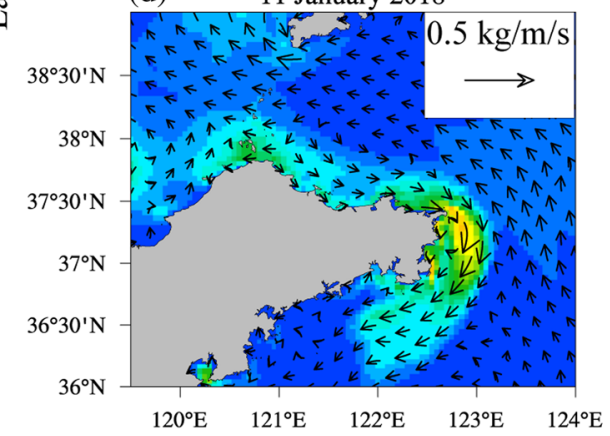

(b)

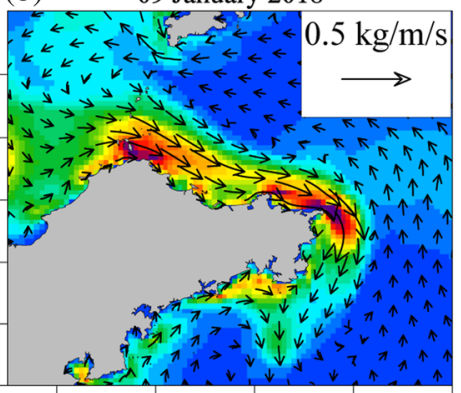

(e)

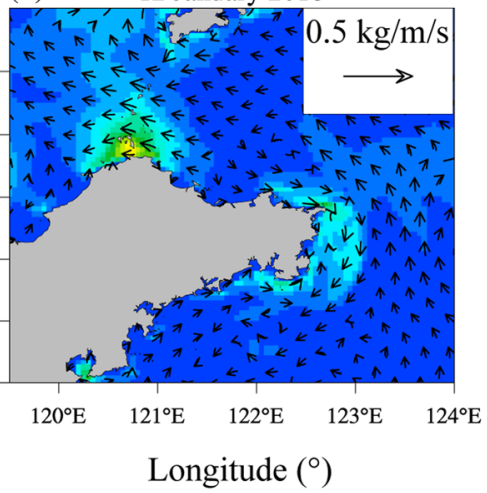

(c) 10 January 2018

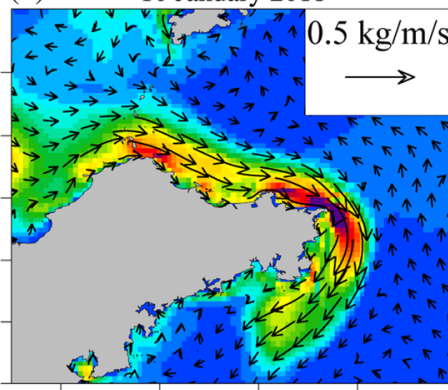

$\mathrm{mg} / \mathrm{L}$

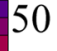

40

30

(f)

13 January 2018

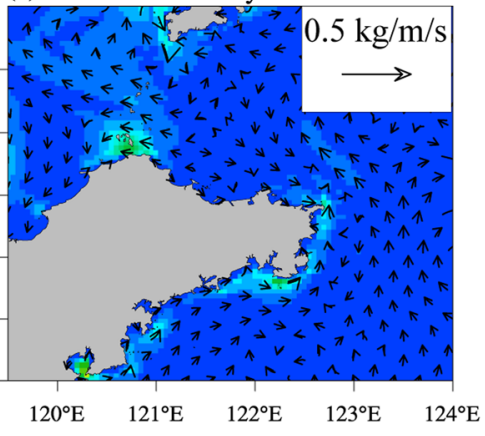

Figure 9. Spatial distributions of daily, depth-averaged SSC and the daily, depth-integrated sediment flux vectors.

occurred in the shallow-water area of the Bohai Strait (Figure 9a), reaching a maximum value of about $100 \mathrm{mg} / \mathrm{L}$. Carried by the wind-driven outflow, large amounts of suspended sediments from the Bohai Sea were transported eastward across the Bohai Strait, then turned clockwise wrapping around the east tip of the Shandong Peninsula, and eventually dispersed in the Southern Yellow Sea. Over the duration of the storm, the magnitude of the SSF was greatest over the southern shallow portion of the Bohai Strait, where wave motion was more dominant. In contrast, the SSF in the northern deep channel was of a much smaller magnitude and in the opposite direction of the wind (Figures $9 \mathrm{~b}$ and 9c). This is largely because of the intrusion of YSWC flowing westward entering the Bohai Sea. When the northerly wind relaxed (11-13 January), water in the Northern Yellow Sea expanded into the Bohai Sea through the Bohai Strait, resulting in westward SSF across the entire strait (Figures 9d-9f). However, as the wind subsided and the wave energy rapidly reduced, the sediment concentrations in the strait also quickly declined. Consequently, the westward SSF through the strait during the relaxation period was much smaller than the eastward flux calculated during the storm buildup phase. This asymmetry is responsible for the fact that the vast majority of sediment flux during this storm occurred in an eastward direction (from the Bohai Sea to the Yellow Sea).

\section{Discussion}

\subsection{What Controls the Exchange Flow Variations?}

In winter, generalized traditional views are that the extension of the YSWC enters the Bohai Sea through the deeper, northern channel of the Bohai Strait, while the eastward NSCC flows out through the shallow, southern section (Guan, 1994; Zhang et al., 2018). However, the monthly or seasonal mean circulation pattern cannot explain the exchange flow's variation over synoptic time scales. Our observational data showed that the exchange flows in the Bohai Strait were characterized by barotropic fluctuations that also displayed a complicated and varying pattern associated with weather systems. Our model results revealed that the two leading EOF modes (EOF1 and EOF2) accounted for $96 \%$ of the total variance (Figure 7). During the observation period (8-13 January), the exchange flows in the strait responded rapidly to synoptic wind forcing, with a short time lag, especially in the shallow-water area of the southern Bohai Strait (Figures $6 \mathrm{~m}$ and 6o). In contrast, the inflow on the deeper side of the strait was in the opposite direction to the coastal current 
(9 January, see Figures $6 \mathrm{n}$ and $6 \mathrm{p}$ ), even in the opposite direction to the strong winds, and lagged more than 1 day behind the peak wind. This strongly suggested that the inflow on the deeper side of the strait was not directly driven by local winds. To our knowledge, it was most likely controlled by wind-triggered CTWs. The CTWs generated by storm events may propagate cyclonically over the continental shelf (Brink, 1991). In particular, the CTW-induced along-shelf currents tend to be in quasi-geostrophic balance with the cross-shelf pressure gradient (Li \& Huang, 2019).

In order to investigate whether CTWs propagation in the semi-enclosed basin can influence exchange flow variations in the Bohai Strait, the model was run without tidal forcing (EXP4), but with diagnostic momentum terms enabled. A classic Yellow Sea CTW theory (Hsueh \& Pang, 1989) shows that a winter storm can trigger two shelf waves on the Chinese shelf and Korea shelf that propagate in opposite directions. Figure 10 plots the simulated SSH (without tide) at a 3-hr interval during the storm buildup phase. When the storm first arrived, negative SSH primarily occurred in the Bohai Sea and Northern Yellow Sea (Figures 10a-10d). About half a day later, a wave with high SSH emerged on the eastern shelf of the Yellow Sea while another wave with low SSH was found on the western shelf (red and blue arrows in Figure 10e). Both of them had maximum amplitudes in the offshore region (Figure 10e). The two sets of waves propagated in opposite directions, consistent with the features of shelf waves. To check whether the induced currents were in quasi-geostrophic balance, the depth-averaged momentum terms are examined against propagating shelf wave theory.

The depth-averaged momentum equation in Cartesian coordinates is written following Liu and Gan (2014):

$$
\begin{gathered}
\overbrace{\frac{\partial \bar{u}}{\partial t}}^{A C C E L_{x}}=\overbrace{f \bar{v}}^{C O R_{x}} \overbrace{-[(\bar{u}, \bar{v}) \cdot \nabla] \bar{u}}^{H A D V_{x}}-\overbrace{g \eta_{x}}^{P G F_{x}}+\overbrace{\frac{\tau_{s x}}{\rho_{0} D}-\frac{\tau_{b x}}{\rho_{0} D}}^{S S T R_{x}}+\overbrace{K_{h} \nabla^{2} \bar{u}}^{B S T R_{x}}, \\
\overbrace{\frac{\partial \bar{v}}{\partial t}}^{H V I S C_{x}}=\overbrace{-f \bar{u}-[(\bar{u}, \bar{v}) \cdot \nabla] \bar{v}}^{C O R_{y}} \overbrace{-g \eta_{y}}^{\text {HADV }}+\overbrace{\frac{\tau_{s y}}{\rho_{0} D}-\frac{\tau_{b y}}{\rho_{0} D}}^{\text {PGF }}+\overbrace{K_{h} \nabla^{2} \bar{v}}^{\text {SSTR }},
\end{gathered}
$$

where subscripts $x$ and $y$ denote the zonal and meridional directions, respectively. $D$ is the depth, and $\rho_{0}$ is the reference density. The variables $\tau_{s x}, \tau_{s y}, \tau_{b x}$, and $\tau_{b y}$ are the surface and bottom stresses. The SSH is represented by $\eta$. The terms in Equations 4 and 5 are acceleration (ACCEL), Coriolis force (COR), horizontal nonlinear advection $(H A D V)$, pressure gradient force $(P G F)$, surface wind stress $(S S T R)$, frictional bottom stress (BSTR), and the horizontal viscous term (HVISC). In this study, the nonlinear advection and horizontal viscous terms ( $H A D V$ and $H V I S C$ ) could be neglected due to their low magnitudes, to focus on the geostrophic balance terms ( $P G F$ and COR). Depth-averaged momentum terms were computed every $3 \mathrm{hr}$. Snapshots of momentum at three-time points (8 January at 12:00, 9 January at 00:00, and 9 January at 12:00; the blue rectangle in Figure 10) were selected to represent the different stages of the shelf wave propagation during the storm buildup phase. Horizontal distribution of subtidal, depth-averaged pressure gradient force terms ( $P G F x$ and PGFy), Coriolis force terms (CORx and CORy) and frictional terms ( $F x$ and Fy, i.e., combined effect of wind stress SSTR and bottom stress BSTR) in zonal $(x)$ and meridional $(y)$ directions were shown in Figure 11.

Water in the Bohai Sea flowed southeastward driven by the northerly wind and accumulated along the northern coast of the Shandong Peninsula, where PGFy was higher than other regions (Figure 11e). The distinctly negative CORy in the Bohai Strait indicated the enhanced eastward coastal current, which reacted concurrently to the northwesterly wind. As shelf waves formed on the Southern Yellow Sea, the high SSH signal occupied the eastern shelf, and a low SSH signal was confined to the western shelf. Consequently, a westward pressure gradient force, as represented by a negative anomaly of PGFx, was gradually established in the middle of the Yellow Sea (black rectangles in Figures 11b, 11h, and 11n). Due to geostrophic adjustment, northward upwind flow YSWC appeared along the Yellow Sea Trough with a positive anomaly of CORx (black rectangle in Figures 11c, 11i, and 110) and then evolved into the Bohai Sea through the deep region of the Bohai Strait. Thus, negative PGFy occurred on the northern side of the Bohai Strait, followed by positive CORy, indicating the generation of inflow in the deep channel of the strait (Figures 11q and 11r). 

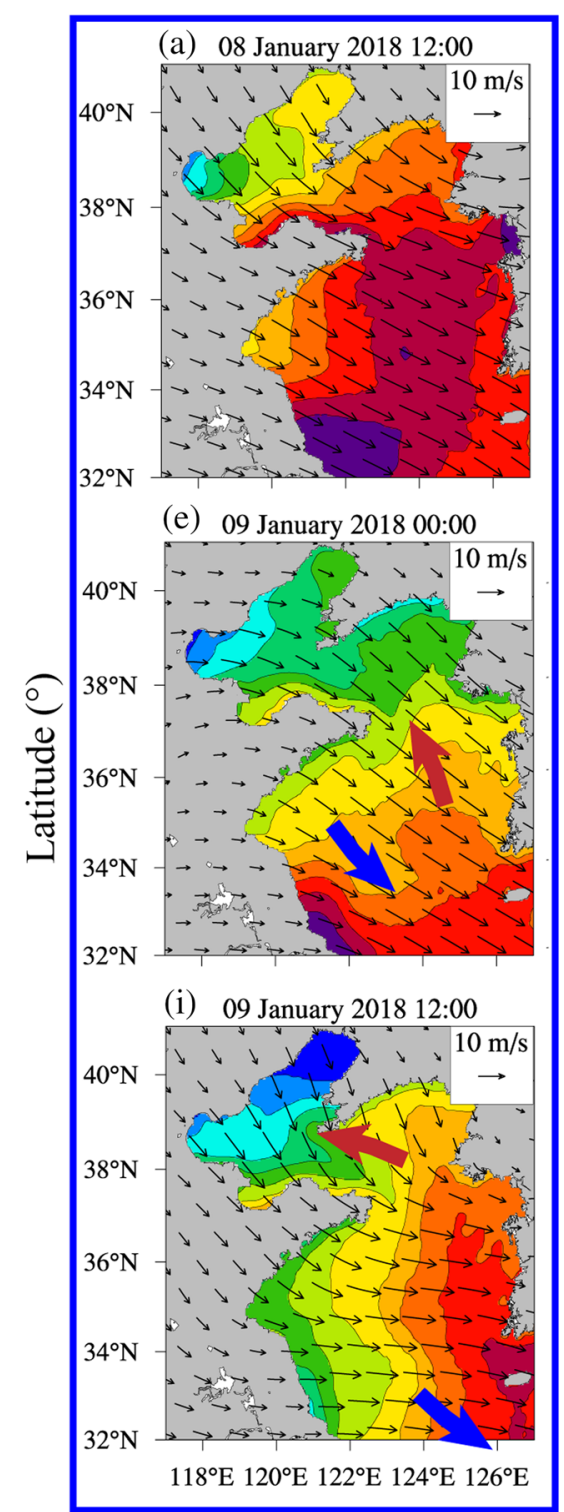

(b) 08 January 2018 15:00
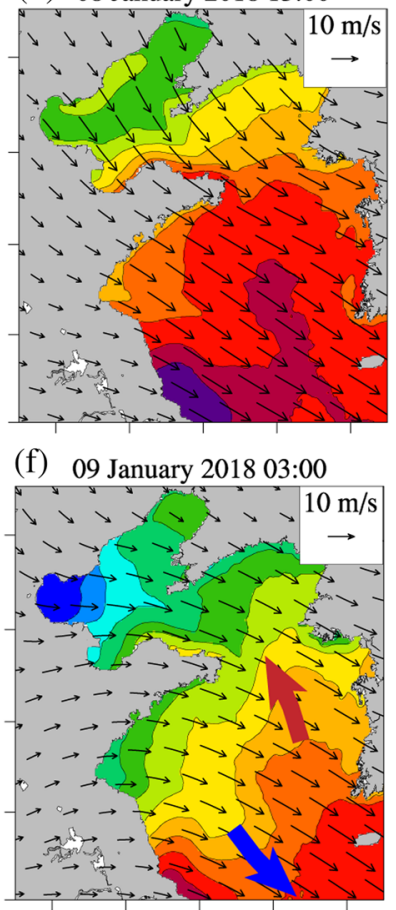

(j) 09 January 2018 15:00

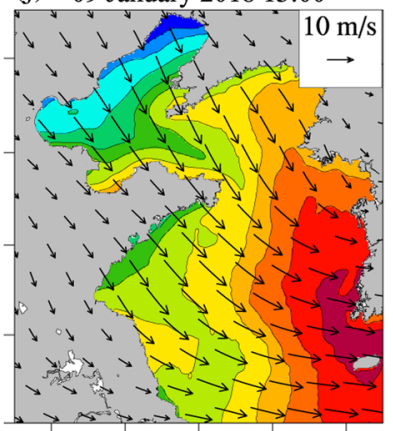

$118^{\circ} \mathrm{E} 120^{\circ} \mathrm{E} 122^{\circ} \mathrm{E} 124^{\circ} \mathrm{E} 126^{\circ} \mathrm{E}$ (c) 08 January 2018 18:00

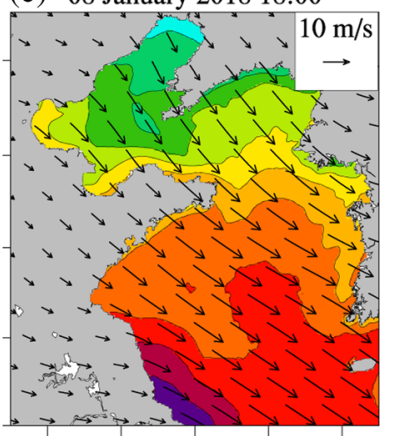

(g) 09 January 2018 06:00

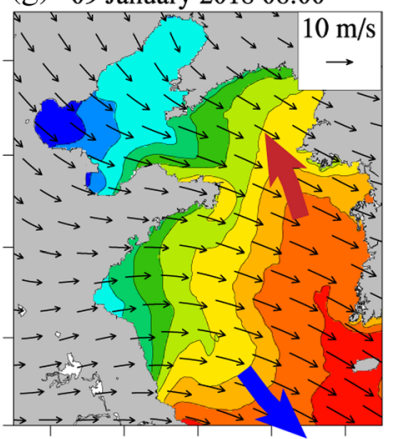

(k) 09 January 2018 18:00

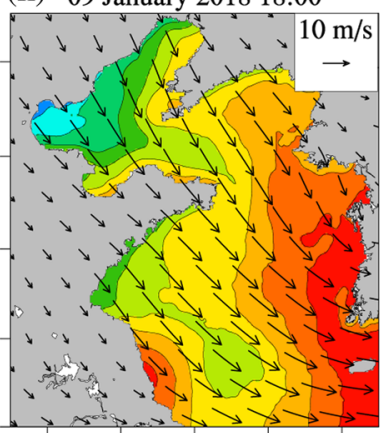

$118^{\circ} \mathrm{E} 120^{\circ} \mathrm{E} 122^{\circ} \mathrm{E} 124^{\circ} \mathrm{E} 126^{\circ} \mathrm{E}$ (d) 08 January 2018 21:00

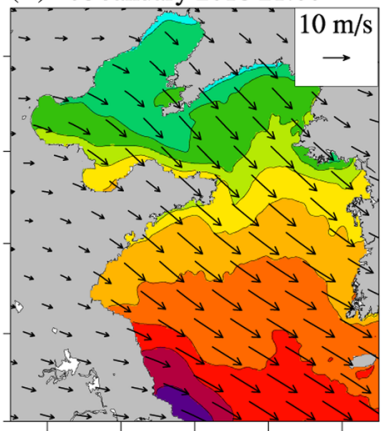

(h) 09 January 2018 09:00 $\mathrm{SSH}(\mathrm{m})$

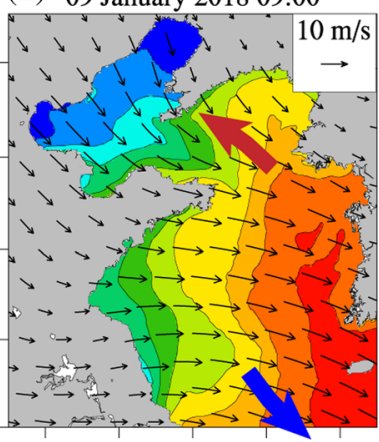

(1) 09 January 2018 21:00

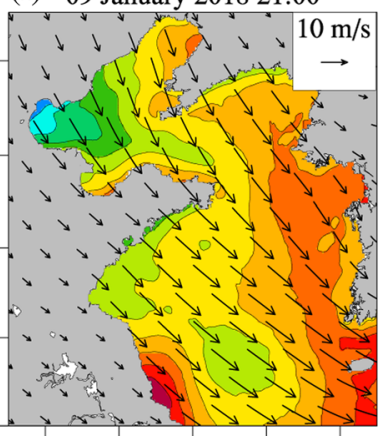

$118^{\circ} \mathrm{E} 120^{\circ} \mathrm{E} 122^{\circ} \mathrm{E} 124^{\circ} \mathrm{E} 126^{\circ} \mathrm{E}$

Figure 10. Snapshots of surface wind used in the model (from ERA-Interim) and evolution of simulated SSH (model run without tide) at 3-hr intervals during the storm buildup phase. Thick arrows show the propagation direction of shelf waves. Blue rectangle (panels a, e, i) is the time used for the momentum terms analysis.

After the relaxation of the northerly wind (11 January), both the observations and simulation results showed that inflow occurred at both the shallow and deep-channel sites of the strait (see Figures 6m-6p). Repeated surveys in the Bohai Strait also revealed that the strait was dominated by inflow when a northerly wind turned to southerly (Wu et al., 2019a). As proposed by Jacobs et al. (1998), synoptic winter storms can generate Kelvin waves in the Bohai Sea and then subsequently propagate southward along the Chinese coast in the northerly wind relaxation period. The prominent feature of the Kelvin wave is that the amplitude is maximum at the coast and decays exponentially offshore (Li \& Huang, 2019). Snapshots of simulated SSH in the northerly wind relaxation phase were shown in Figure 12. At 00:00 on 11 January, the amplitude of SSH was lowest on the northern coast of the Bohai Sea and gradually increased from north to south (Figure 12a). The spatial pattern and the direction of propagation were consistent with Kelvin waves. As the wind direction turned from northwest to west, the low SSH signal begun to propagate eastward and southward along the coastline of China. 
Momentum terms in zonal (x) direction 08 January 12:00 (a-f)

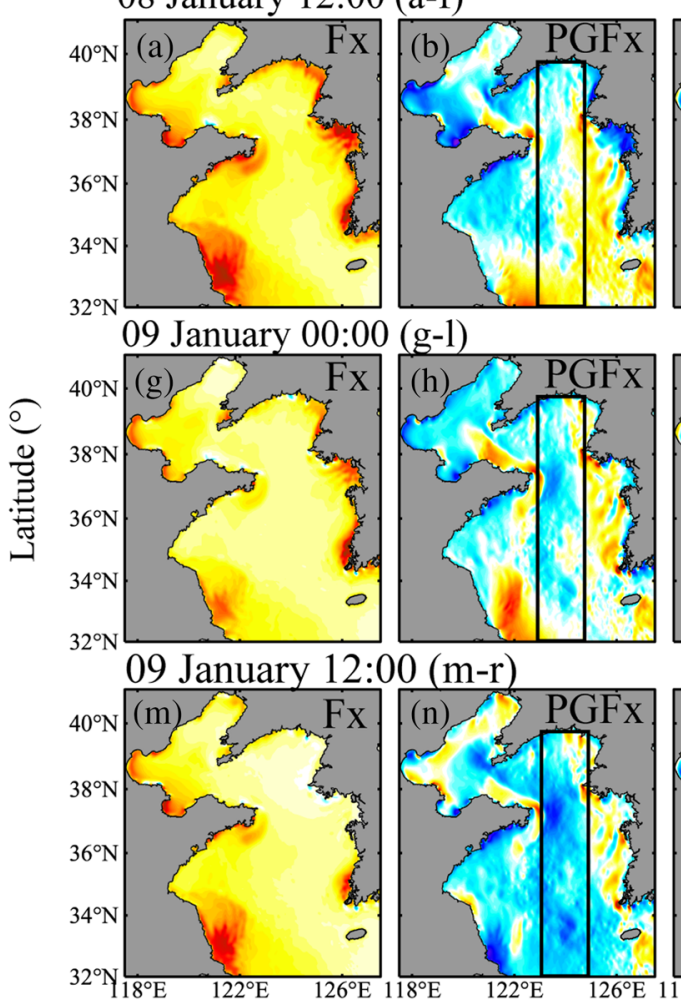

\section{Momentum terms in meridional $(\mathrm{y})$ direction}
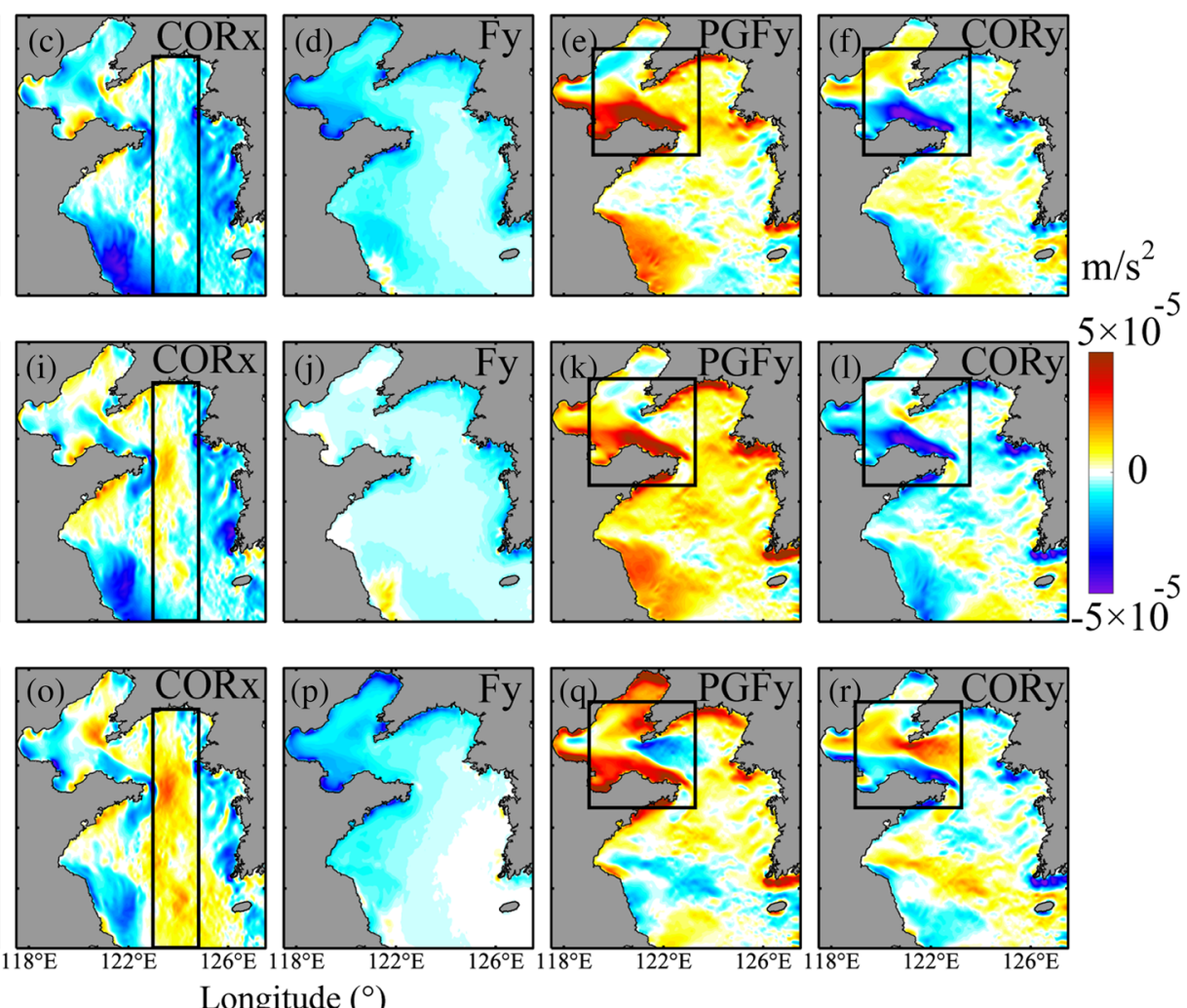

Longitude $\left({ }^{\circ}\right)$

Figure 11. Horizontal distribution of depth-averaged momentum terms in Equations 4 and 5 on 8 January (12:00), 9 (00:00), and 9 (12:00), 2018: (a, g, m) friction terms in zonal direction, $(b, h, n)$ pressure gradient force terms in zonal direction, $(c, i, o)$ Coriolis force terms in zonal direction, (d, $j$, $p$ ) friction terms in meridional direction, $(\mathrm{e}, \mathrm{k}, \mathrm{q})$ pressure gradient force terms in meridional direction, and (f, l, r) Coriolis force terms in meridional direction. Positive values represent the eastward in the zonal terms and northward in the meridional terms.

To further investigate how Kelvin waves affected the exchange flow variation in the Bohai Strait, we examined the meridional ( $y$-direction) momentum terms at two times, 00:00 and 12:00, 11 January (Figure 12g-1). If the Kelvin wave contained a low SSH signal and propagated along the coast, the pressure gradient forces would point to the coastline. The snapshot at 12:00 indicated that the Kelvin wave was passing the Bohai Strait (Figure 12e). At that time, low SSH occupied the southern side of the Bohai Strait, and the SSH gradually increased from south to north. Figures $12 \mathrm{~h}$ and $12 \mathrm{k}$ revealed that the pressure gradient terms certainly changed. The negative PGFy term (Figure 12e) and the positive CORy term (Figure 12f) under the geostrophic effect indicate an inflow occupying the entire strait. Spatial distribution of the CORy terms clearly showed that the exchange flow pattern changed from "north-inflow and south-outflow" at 00:00 (11 January) (Figure 12i) to a strait-wide inflow at 12:00 (11 January) (Figure 12l).

The findings in CTWs propagation further illustrate that the exchange in the bay-shelf system is not only regulated by local winds but also affected by dynamic processes far from the strait, such as shelf waves generated in the Yellow Sea. The northward propagation of the shelf wave on the eastern side of the Yellow Sea into the deep channel of the Bohai Strait, that is, the western side of the Yellow Sea is characteristically similar to Qu et al.'s (2018) findings in their idealized double-shelf basin experiments: that topographic connection can guide shelf wave propagation from one side to the other. This mechanism reasonably explains why the exchange flow patterns in the strait have three phases: strait-wide outflow, north-inflow and southoutflow, and strait-wide inflow during the storm event. And it further helps to explain why the wintertime-averaged exchange flows of the Bohai Strait show a "north-inflow and south-outflow" pattern under the influence of frequently occurring storms. 

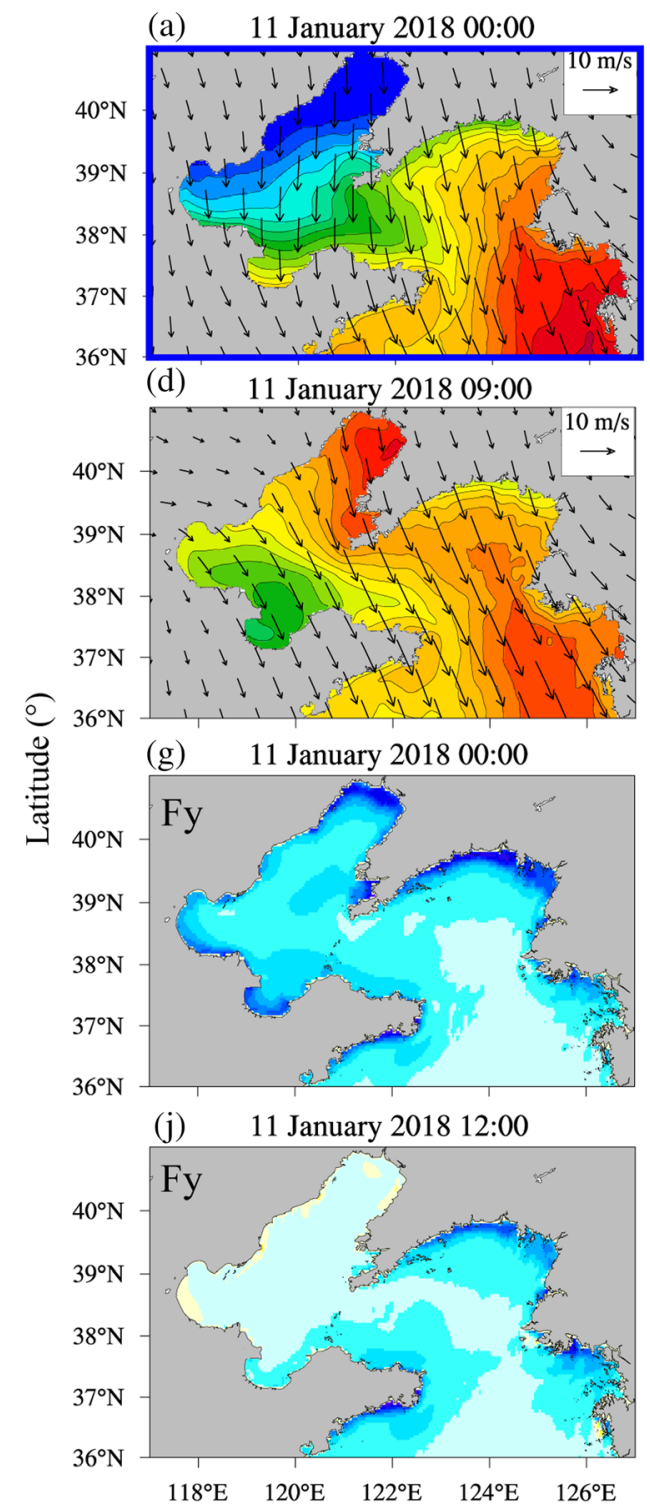
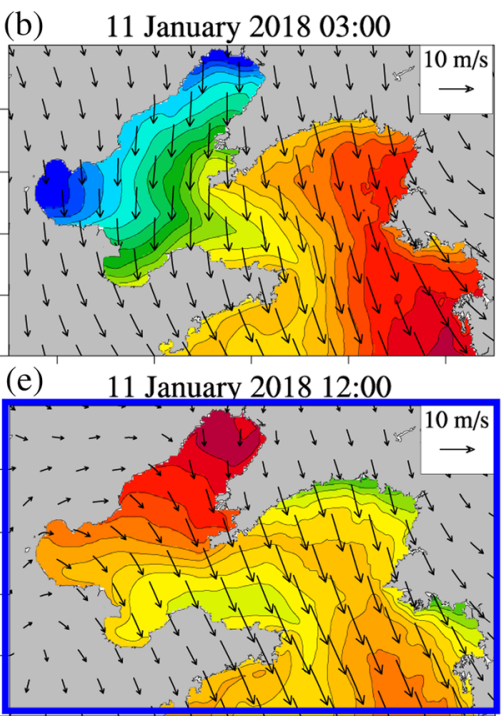

(h) 11 January 2018 00:00

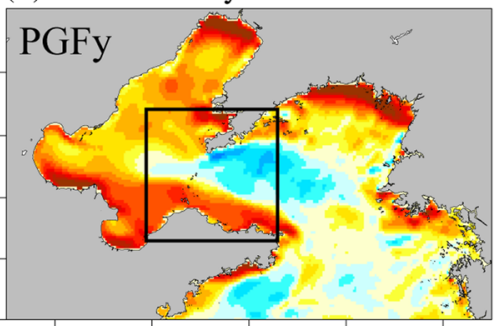

(k) 11 January 2018 12:00

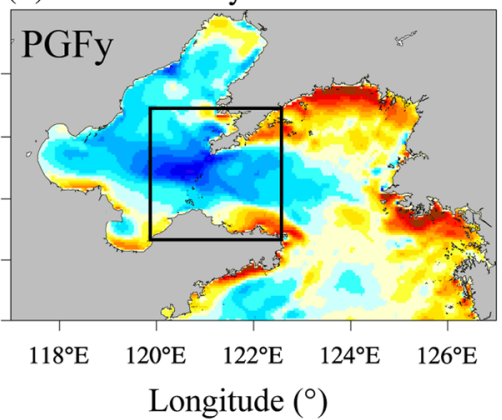

(c) 11 January 2018 06:00

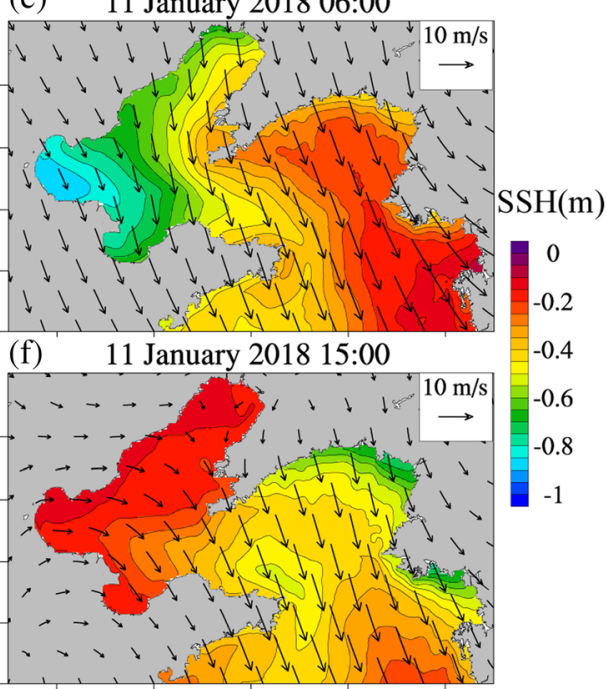

(i) 11 January 2018 00:00

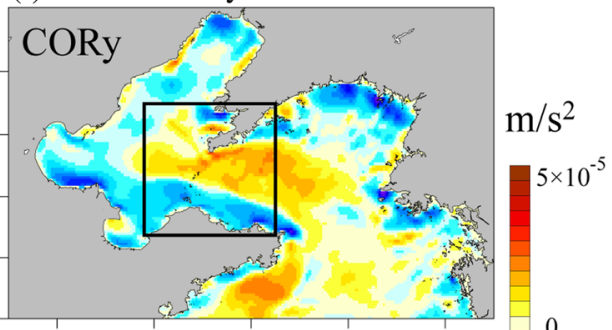

(1) 11 January 2018 12:00

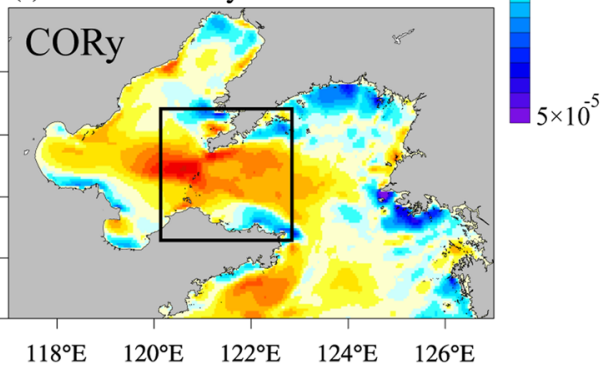

Figure 12. (a-f) Snapshots of surface wind used in the model (from ERA-Interim) and evolution of simulated SSH (model run without tide) at 3-hr intervals during the northerly wind relaxation phase. (g-l) Horizontal distribution of depth-averaged momentum terms in meridional direction: (g, $\mathrm{j}$ ) friction terms, (h, k) pressure gradient force terms, and (i, l) Coriolis force terms, at 00:00 and 12:00 (11 January 2018) (panels a and e).

\subsection{Net Sediment Flux and the Fluctuating Exchange Flow}

Previous studies speculated that the formation of the mud clinoform off the Shandong Peninsula (see Figure $1 \mathrm{~b}$ ) is directly related to the coastal current flowing from the Bohai Sea to the Yellow Sea (Xue et al., 2018; Yang \& Liu, 2007; Wu et al., 2019b). Exchange flow between the Bohai Sea and the Yellow Sea ultimately determines the long-term exchange of oceanic water and sediment. However, a recent well-designed PAM survey in the Bohai Strait showed that sediment was transported from the Yellow Sea into the Bohai Sea after a northerly wind event (Wu et al., 2019a). Clearly, numerical models that rely on monthly averaged or seasonally averaged wind fields neglected those critical extreme events. Accounting for episodic storms is one of the main reasons that a quantitative sediment budget through the strait remains elusive. In fact, as our observations and model results revealed, the winter-time exchange flow in the strait fluctuates, rather than maintaining a stable "north-inflow and south-outflow" structure. A major question is: How the fluctuations in exchange flow contribute to net sediment flux? 
Full simulation model

(a) Wave-induced shear stress

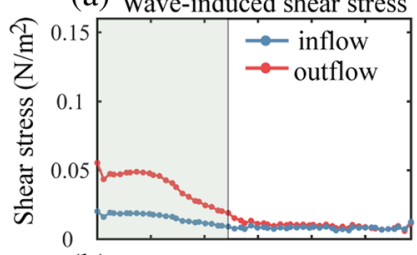

(b) Current-induced shear stres

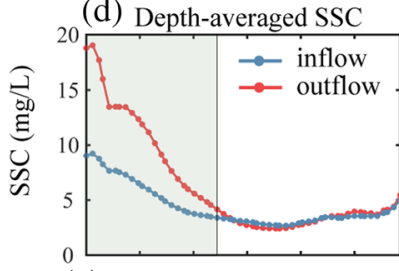

(e) Depth-averaged exchange flow

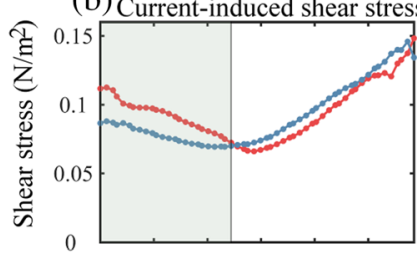

(c) Max wave-current stress
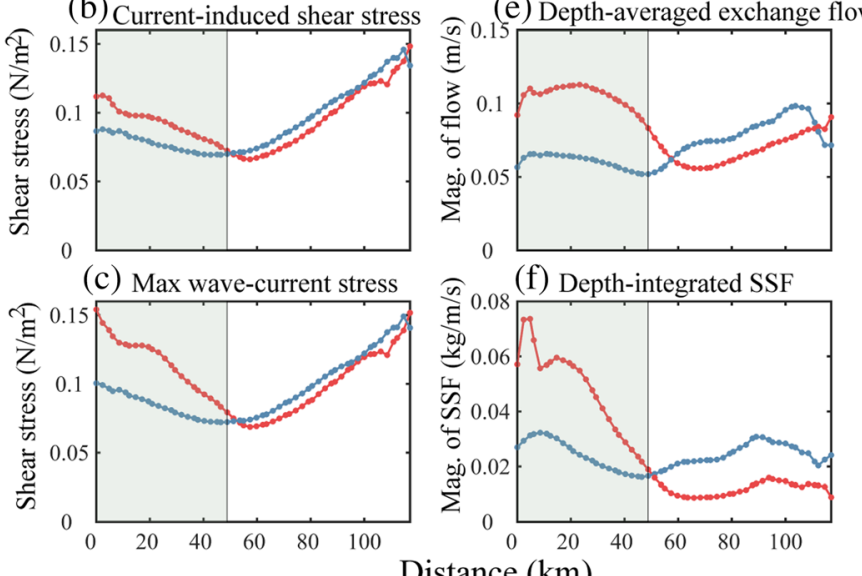

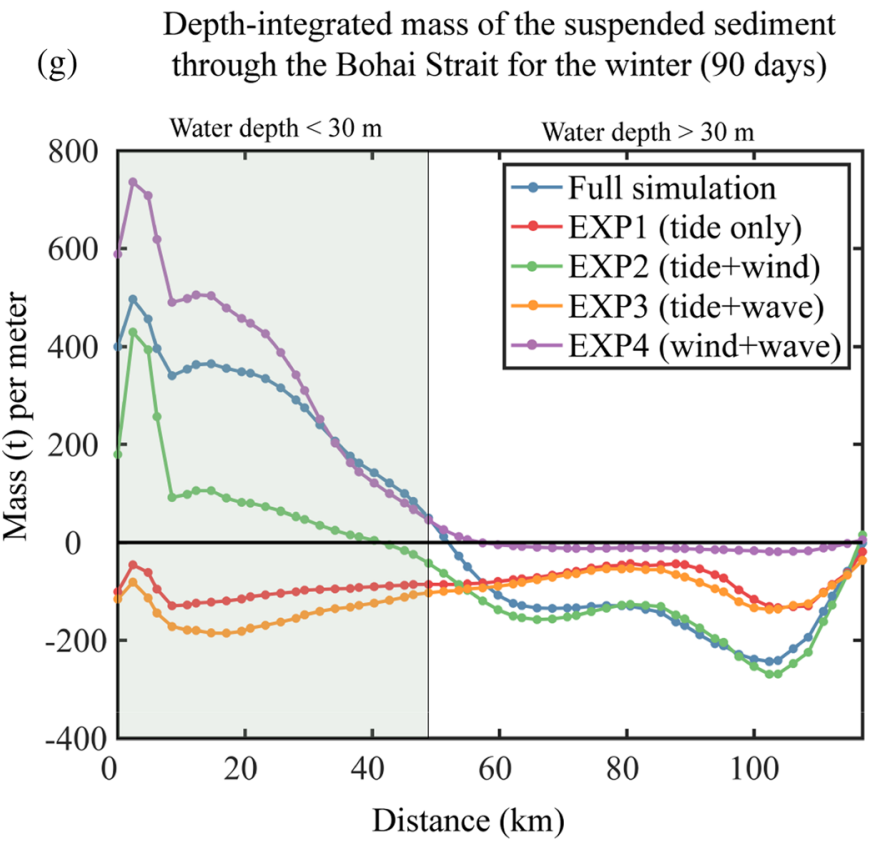

Depth-integrated mass of the suspended sediment

Figure 13. (a-f) Time-averaged hydrodynamic characteristics across Bohai Strait under outflow and inflow conditions, respectively, from December 2017 to February 2018. (g) Depth-integrated mass of suspended sediment through the Bohai Strait for the winter (90 days). Positive values indicate sediment transport from the Bohai Sea to the Yellow Sea. The shaded area represents the shallow region with water depth less than $30 \mathrm{~m}$.

Figures 13a-13f plot the cross-strait mean properties separately averaged for inflow and outflow conditions over the entire winter (December 2017-February 2018, 90 days) based on the model results. Strong northerly winds generate net sediment flux through the Bohai Strait in two different ways. First, the inflows and outflows are driven by different mechanisms. The intensity of time-averaged outflows exceeds inflows on the shallow, southern side of the strait (Figure 13e). On the northern, deep-channel side, however, inflows are stronger than outflows (Figure 13e). From the long-term perspective, the difference between the inflow and outflow magnitudes must influence the temperature/salinity distribution as well as sediment transport pathways, for example, the so-called "north-inflow and south-outflow" exchange flow patterns through the Bohai Strait. Second, during the storm buildup phase (dominated by outflow conditions), elevated bed shear stresses by the energetic waves and enhanced coastal current cause strong sediment resuspension and much higher SSC compared to the inflow-dominated wind relaxation phase, especially in the shallow area (shading area in Figures 13a-13d). Despite occasional westward sediment transport into the Bohai Sea (Wu et al., 2019a), the most significant transport over the duration of an entire winter is from the Bohai Sea to the Yellow Sea.

\subsection{The Relative Contribution to the Net Sediment Flux}

The observations and model results showed that large net sediment fluxes occur during winter storms; however, the instantaneous flux through the strait is also highly dependent on tidal currents (Figures 7g-7i). To clarify the relative contribution of tides, winds, and surface waves to sediment flux through Bohai Strait, we conducted four model experiments and for each calculated the depth-integrated suspended sediment mass through the strait for the whole winter (Figure 13g). The full simulation model (FSM) included tides, winds, and waves, so it accounted for the fluctuating exchange flow and enhanced bottom shear stress under wave-current interaction. However, models without winds (EXP1 and EXP3) did not represent the fluctuating exchange flow, and models without waves (EXP1 and EXP2, no coupling with the SWAN model) did not account for wave-induced shear stress.

In the shallow-water region (shaded area of Figure 13g), the models that included winds produced fluctuating exchange flows (FSM, EXP2, and EXP4) that generated net sediment transport from the Bohai Sea to the Yellow Sea. However, the models that neglected winds (EXP1 and EXP3) produced net sediment flux in the 
(a) Northerly wind buildup
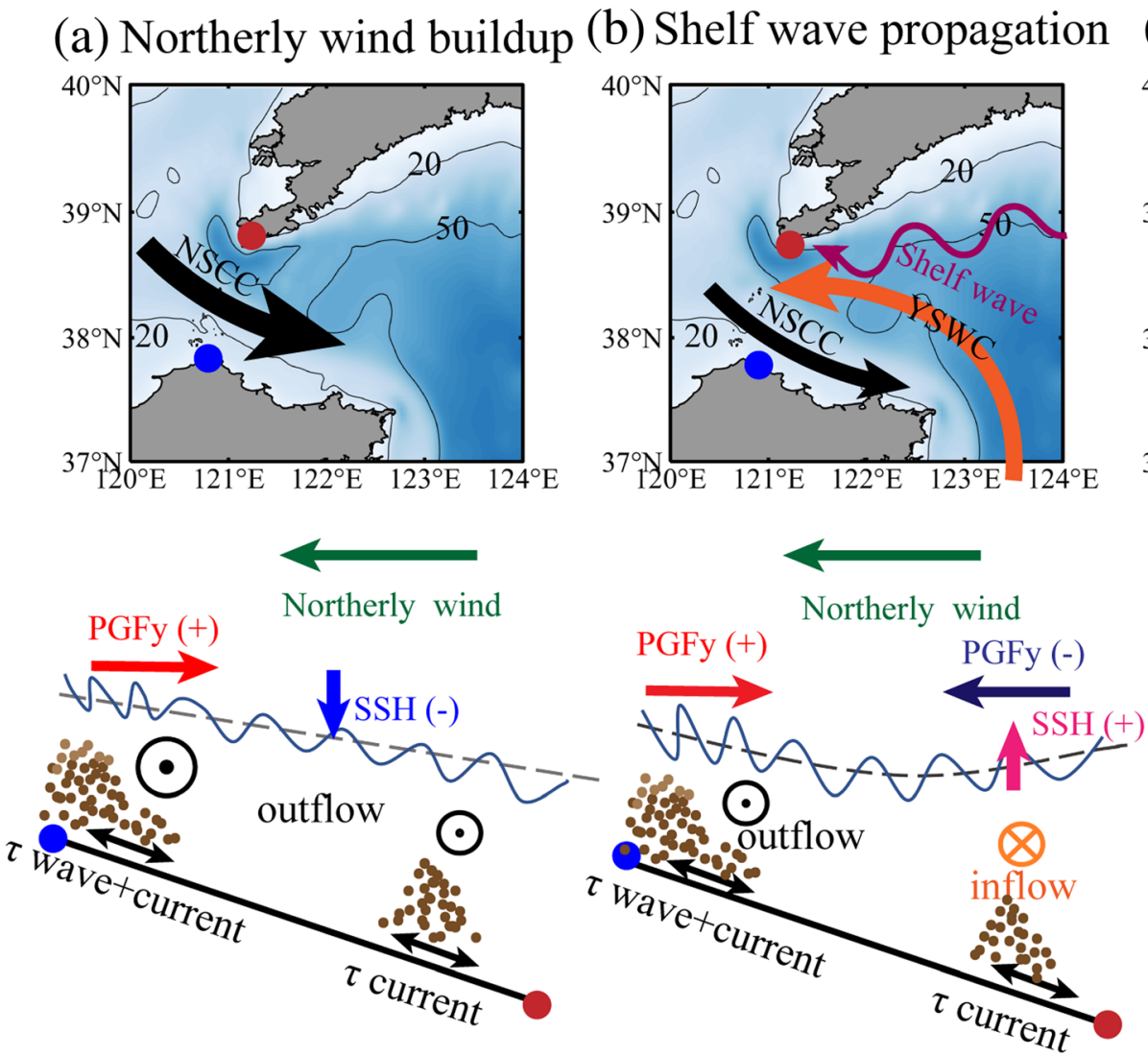
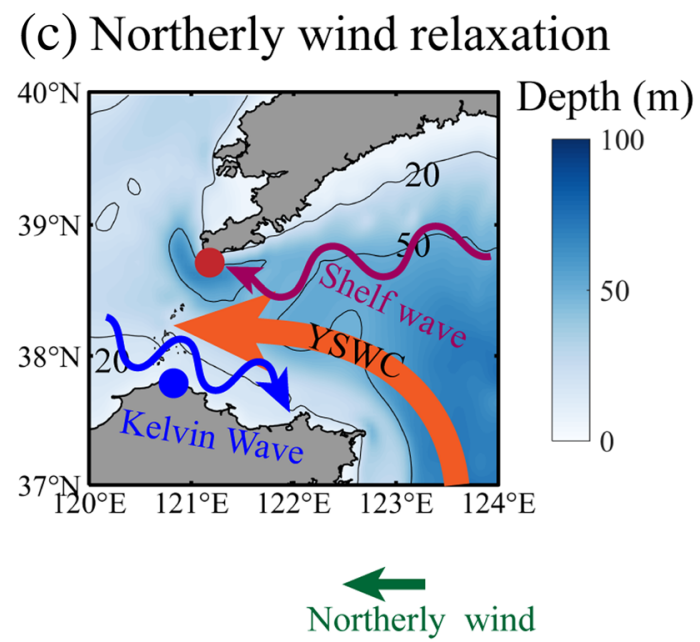

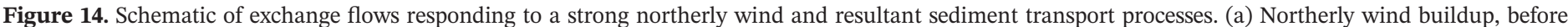

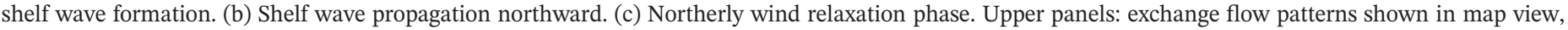

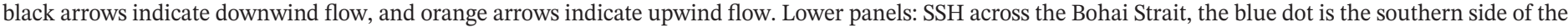

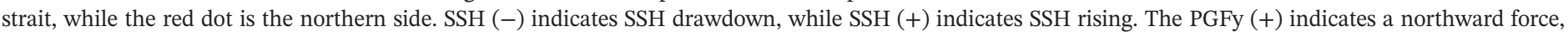
while PGFy (-) indicates southward force.

opposite direction, because in the absence of wind-induced currents during winter storms, the direction of sediment transport depended mainly on the tide. On the southern side of the strait, wind and wave-driven transport during storms tended to move sediment from the Bohai Sea to the Yellow Sea. Therefore, the net wintertime transport between the Bohai Sea and the Yellow Sea in the shallow-water region of the strait depends on the frequency and intensity of winter storms. The deep-water locations always had net sediment transport to the Bohai Sea, regardless of whether the model included winds or waves (Figure 13g). In particular, models that included both tides and winds (FSM and EXP2) produced the largest transport, because the propagation of the shelf waves significantly increased inflow on the northern side. The calculated sediment flux magnitude may be sensitive to the choice of sediment parameters, but the general patterns are not expected to change. Additionally, our sediment model neglected bedload transport, and it may underestimate sediment flux, especially on the northern side of the strait. However, the sediment transport pattern of the strait will not be greatly affected, because the magnitude of the bedload is much smaller than the suspended load in the Bohai Strait (Qi et al., 2020).

\section{Summary/Conclusions}

Using in situ observations and model simulations, the synoptic variations of exchange flow through the Bohai Strait and the dynamic mechanisms for sediment transport are investigated. The exchange flow shows a complex response to strong northerly winds that frequently occur in winter, which is generalized in Figure 14. During the northerly wind buildup phase, SSH in the Bohai Sea drops sharply and water piles up along the northern coast of the Shandong Peninsula, thereby forming a northward pressure gradient 
force, and intensified eastward alongshore currents (Figure 14a). Additionally, northerly winds trigger two sets of shelf waves in the Yellow Sea. Our momentum term analyses show that the shelf waves provide the pressure gradient force in the zonal direction (east-west) in the Yellow Sea while providing the pressure gradient force in the meridional direction (south-north) in the Bohai Strait. As a result, inflow is formed on the north side of the strait under the effect of geostrophic balance. At that time, wind-driven coastal currents persist on the south, so the circulation pattern is "north-inflow and south-outflow" (Figure 14b). When the Kelvin waves carrying a low SSH signal pass through the strait, they form a southward pressure gradient force in the meridional direction, resulting in strait-wide inflow conditions (Figure 14c). Two typical exchange flow patterns are revealed by EOF analysis. The dominant mode represents strait-wide inflow and outflow alternating through the strait. The minor mode represents concurrent inflow and outflow over different sections of the strait. The cumulative effect of the two flow patterns makes the "north-inflow and south-outflow" structure the dominant pattern in wintertime.

The strong tidal currents in the Bohai Strait not only influence sediment resuspension but also provide a mechanism for sediment transport from the Yellow Sea to the Bohai Sea (EXP1 and EXP3, Figure 13g). Although the instantaneous SSF is highly aligned with the tidal current, the occurrence of winter storms, however, dramatically changes the flow dynamics and the direction of net sediment transport. The wind-induced oscillating barotropic flows are an order of magnitude larger than the tidally induced residual flow and therefore determine the pattern of net sediment transport. Over the duration of a storm, strong northerly winds predominantly drive eastward outflow, while the propagation of CTWs is responsible for westward inflow. Furthermore, during outflow conditions, stronger coastal current, combined with enhanced wave-current interaction, significantly increase suspend sediment concentration along the southern shallow portion of the strait. This increases SSC on the southern shallow portion of the strait, giving rise to an eastward (outflow) SSF there that greatly exceeds the inflow conditions. The wintertime net sediment transport through Bohai Strait is primarily the result of SSF asymmetries between inflows (CTW driven) and outflows (wind driven). By providing a better understanding of the mechanisms of sediment transport through the strait, this study lays a foundation to explain the sedimentary evolution of the mud clinoform offshore of the Shandong Peninsula. In addition, the relationship between the evolution of CTWs and the through-strait exchange processes may potentially be relevant to similar coupled bay-shelf systems.

\section{Data Availability Statement}

The HYCOM + NCODA Global 1/12 ${ }^{\circ}$ Analysis data were from the Web site (http://tds.hycom.org/thredds/ catalog.html/). Wind data were downloaded from the ERA-Interim database (https://www.ecmwf.int/). The model data used in this paper are available online (https://figshare.com/s/287483b052497b995a06).

\section{Acknowledgments}

We sincerely express our thanks to the developers of the ROMS model and appreciate the guidance of Prof. Wensheng Jiang from the Ocean University of China. Thanks also to Dr. Lixin Qu from Stanford University for the useful scientific discussions about coastal trapped waves. This study has been supported by the National Natural Science Foundation of China (NSFC, Grants 41530966, 41476070, and 41525021), and Taishan Scholar Project of Shandong Province (TS20190913). The crew members of $\mathrm{R} / \mathrm{V}$ DONGFANGHONG 2 are also appreciated for their efforts on cruise observations. This paper is contribution number 3902 of the Virginia Institute of Marine Science, William \& Mary. Finally, we appreciate the input of two anonymous reviewers, whose insight and comments have helped us to improve the manuscript.

\section{References}

Berrisford, P., Dee, D. P., Fielding, K., Fuentes, M., Kållberg, P. W., Kobayashi, S., \& Uppala, S. M. (2009). The ERA-Interim Archive. ERA Report Series. 1. Technical Report. European Centre for Medium-Range Weather Forecasts, Shinfield Park, Reading. pp16.

Bi, N., Yang, Z., Wang, H., Fan, D., Sun, X., \& Lei, K. (2011). Seasonal variation of suspended-sediment transport through the southern Bohai Strait. Estuarine, Coastal and Shelf Science, 93(3), 239-247. https://doi.org/10.1016/j.ecss.2011.03.007

Bian, C., Jiang, W., Quan, Q., Wang, T., Greatbatch, R. J., \& Li, W. (2013). Distributions of suspended sediment concentration in the Yellow Sea and the East China Sea based on field surveys during the four seasons of 2011. Journal of Marine Systems, 121-122, 24-35. https://doi. org/10.1016/j.jmarsys.2013.03.013

Booij, N., Ris, R. C., \& Holthuijsen, L. H. (1999). A third-generation wave model for coastal regions: 1. Model description and validation. Journal of Geophysical Research, 104(C4), 7649-7666. https://doi.org/10.1029/98JC02622

Brink, K. H. (1991). Coastal-trapped waves and wind-driven currents over the continental shelf. Annual Review of Fluid Mechanics, 23(1), 389-412. https://doi.org/10.1146/annurev.fl.23.010191.002133

Chapman, D. C. (1985). Numerical treatment of cross-shelf open boundaries in a Barotropic Coastal Ocean model. Journal of Physical Oceanography, 15(8), 1060-1075. https://doi.org/10.1175/1520-0485(1985)015<1060:NTOCSO>2.0.CO;2

Cottier, F., Nilsen, F., Skogseth, R., Tverberg, V., Skardhamar, J., \& Svendsen, H. (2010). Arctic fjords: A review of the oceanographic environment and dominant physical processes. Fjord Systems and Archives, Special Publications (Vol. 344, pp. 35-50). London: Geological Society. https://doi.org/10.1144/SP344.4

Ding, Y., Bao, X., Yao, Z., Bi, C., Wan, K., Bao, M., et al. (2019). Observational and model studies of synoptic current fluctuations in the Bohai Strait on the Chinese continental shelf. Ocean Dynamics, 69(3), 323-351. https://doi.org/10.1007/s10236-019-01247-5

Ding, Y., Bao, X., Yao, Z., Song, D., Song, J., Gao, J., \& Li, J. (2018). Effect of coastal-trapped waves on the synoptic variations of the Yellow Sea Warm Current during winter. Continental Shelf Research, 167, 14-31. https://doi.org/10.1016/j.csr.2018.08.003

Egbert, G. D., \& Erofeeva, S. Y. (2002). Efficient inverse modeling of barotropic ocean tides. Journal of Atmospheric and Oceanic Technology, 19(2), 183-204. https://doi.org/10.1175/1520-0426(2002)019<0183:EIMOBO>2.0.CO;2 
Fairall, C. W., Bradley, E. F., Hare, J. E., Grachev, A. A., \& Edson, J. B. (2003). Bulk parameterization of air-sea fluxes: Updates and verification for the COARE algorithm. Journal of Climate, 16(4), 571-591. https://doi.org/10.1175/1520-0442(2003)016<0571:BPOASF>2.0. $\mathrm{CO} ; 2$

Fairley, I., Masters, I., \& Karunarathna, H. (2016). Numerical modelling of storm and surge events on offshore sandbanks. Marine Geology, 371, 106-119. https://doi.org/10.1016/j.margeo.2015.11.007

Flather, R. A. (1987). A tidal model of the northeast pacific. Atmosphere-Ocean, 25(1), 22-45. https://doi.org/10.1080/ 07055900.1987 .9649262

Flores, R. P., Rijnsburger, S., Horner-Devine, A. R., Souza, A. J., \& Pietrzak, J. D. (2017). The impact of storms and stratification on sediment transport in the Rhine region of freshwater influence. Journal of Geophysical Research: Oceans, 122, 4456-4477. https://doi.org/ 10.1002/2016JC012362

Geyer, W. R., \& MacCready, P. (2014). The estuarine circulation. Annual Review of Fluid Mechanics, 46(1), 175-197. https://doi.org/ 10.1146/annurev-fluid-010313-141302

Guan, B. X. (1994). Patterns and structures of the currents in Bohai, Huanghai and East China seas. In Z. Di, L. Yuan-Bo, \& Z. Cheng-Kui (Eds.), Oceanology of China seas (pp. 17-26). Dordrecht: Springer Netherlands.

Gutiérrez, M. O., López, M., Candela, J., Castro, R., Mascarenhas, A., \& Collins, C. A. (2014). Effect of coastal-trapped waves and wind on currents and transport in the Gulf of California. Journal of Geophysical Research: Oceans, 119, 5123-5139. https://doi.org/10.1002/ 2013JC009538

Hill, H. W., Kelley, J. T., Belknap, D. F., \& Dickson, S. M. (2004). The effects of storms and storm-generated currents on sand beaches in Southern Maine, USA. Marine Geology, 210(1-4), 149-168. http://pubs.er.usgs.gov/publication/70026745

Hsueh, Y., \& Pang, I.-C. (1989). Coastally trapped long waves in the Yellow Sea. Journal of Physical Oceanography, 19(5), 612-625. https:// doi.org/10.1175/1520-0485(1989)019<0612:CTLWIT>2.0.CO;2

Hu, Z., Wang, D.-P., He, X., Li, M., Wei, J., Pan, D., \& Bai, Y. (2017). Episodic surface intrusions in the Yellow Sea during relaxation of northerly winds. Journal of Geophysical Research: Oceans, 122, 6533-6546. https://doi.org/10.1002/2017JC012830

Huthnance, J. M. (1995). Circulation, exchange and water masses at the ocean margin: The role of physical processes at the shelf edge. Progress in Oceanography, 35(4), 353-431. https://doi.org/10.1016/0079-6611(95)80003-C

Inall, M. E., Nilsen, F., Cottier, F. R., \& Daae, R. (2015). Shelf/fjord exchange driven by coastal-trapped waves in the Arctic. Journal of Geophysical Research: Oceans, 120, 8283-8303. https://doi.org/10.1002/2015JC011277

Jacobs, G. A., Preller, R. H., Riedlinger, S. K., \& Teague, W. J. (1998). Coastal wave generation in the Bohai Bay and propagation along the Chinese coast. Geophysical Research Letters, 25(6), 777-780. https://doi.org/10.1029/97GL03636

Larson, J., Jacob, R., \& Ong, E. (2005). The Model Coupling Toolkit: A new Fortran90 toolkit for building multiphysics parallel coupled models. The International Journal of High Performance Computing Applications, 19(3), 277-292. https://doi.org/10.1177/ 1094342005056115

Li, G., Li, P., Liu, Y., Qiao, L., Ma, Y., Xu, J., \& Yang, Z. (2014). Sedimentary system response to the global sea level change in the East China seas since the last glacial maximum. Earth-Science Reviews, 139, 390-405. https://doi.org/10.1016/j.earscirev.2014.09.007

Li, M., Wu, Y., Han, G., Prescott, R. H., \& Tang, C. C. L. (2017). A modeling study of the impact of major storms on seabed shear stress and sediment transport on the Grand Banks of Newfoundland. Journal of Geophysical Research: Oceans, 122, 4183-4216. https://doi.org/ $10.1002 / 2016 \mathrm{JC} 012215$

Li, M., Wu, Y., Prescott, R. H., Tang, C. C. L., \& Han, G. (2015). A modeling study of the impact of major storms on waves, surface and near-bed currents on the Grand Banks of Newfoundland. Journal of Geophysical Research: Oceans, 120, 5358-5386. https://doi.org/ $10.1002 / 2015 J C 010755$

Li, Z., \& Huang, D. (2019). Sea surface height and current responses to synoptic winter wind in the Bohai, Yellow, and East China seas: Two leading coastal trapped waves. Journal of Geophysical Research: Oceans, 124, 2289-2312. https://doi.org/10.1029/2018JC014120

Lin, X., Yang, J., Guo, J., Zhang, Z., Yin, Y., Song, X., \& Zhang, X. (2011). An asymmetric upwind flow, Yellow Sea Warm Current: 1. New observations in the western Yellow Sea. Journal of Geophysical Research, 116, C04026. https://doi.org/10.1029/2010JC006513

Liu, Z., \& Gan, J. (2014). Modeling study of variable upwelling circulation in the East China Sea: Response to a coastal promontory. Journal of Physical Oceanography, 44(4), 1078-1094. https://doi.org/10.1175/JPO-D-13-0170.1

Lu, J., Qiao, F. L., Wang, X. H., Wang, Y. G., Teng, Y., \& Xia, C. S. (2011). A numerical study of transport dynamics and seasonal variability of the Yellow River sediment in the Bohai and Yellow seas. Estuarine, Coastal and Shelf Science, 95(1), 39-51. https://doi.org/10.1016/j. ecss.2011.08.001

Madsen, O. S. (1995). Spectral wave-current bottom boundary layer flows. Coastal Engineering, 1994, 384-398. https://ascelibrary.org/doi/ abs/10.1061/9780784400890.030

Maio, C. V., Donnelly, J. P., Sullivan, R., Madsen, S. M., Weidman, C. R., Gontz, A. M., \& Sheremet, V. A. (2016). Sediment dynamics and hydrographic conditions during storm passage, Waquoit Bay, Massachusetts. Marine Geology, 381, 67-86. https://doi.org/10.1016/j. margeo.2016.07.004

Marchesiello, P., McWilliams, J. C., \& Shchepetkin, A. (2001). Open boundary conditions for long-term integration of regional oceanic models. Ocean Modelling, 3(1-2), 1-20. https://doi.org/10.1016/S1463-5003(00)00013-5

Martin, J. M., Zhang, J., Shi, M. C., \& Zhou, Q. (1993). Actual flux of the Huanghe (yellow river) sediment to the Western Pacific Ocean. Netherlands Journal of Sea Research, 31(3), 243-254. https://doi.org/10.1016/0077-7579(93)90025-N

Mellor, G. L., \& Yamada, T. (1982). Development of a turbulence closure model for geophysical fluid problems. Reviews of Geophysics, 20(4), 851-875. https://doi.org/10.1029/RG020i004p00851

Milliman, J. D., \& Meade, R. H. (1983). World-wide delivery of river sediment to the oceans. The Journal of Geology, 91(1), 1-21. https://doi. org/10.1086/628741

Mo, D., Hou, Y., Li, J., \& Liu, Y. (2016). Study on the storm surges induced by cold waves in the northern East China Sea. Journal of Marine Systems, 160, 26-39. https://doi.org/10.1016/j.jmarsys.2016.04.002

Naimie, C., Ann Blain, C., Lynch, R., \& D. (2001). Seasonal mean circulation in the Yellow Sea-A model-generated climatology. Continental Shelf Research, 21(6-7), 667-695. https://doi.org/10.1016/S0278-4343(00)00102-3

Nowacki, D. J., \& Ganju, N. K. (2018). Storm impacts on hydrodynamics and suspended-sediment fluxes in a microtidal back-barrier estuary. Marine Geology, 404, 1-14. https://doi.org/10.1016/j.margeo.2018.06.016

Qi, F., Bian, C., \& Xu, J. (2020). Parameterization of sediment transport in the Bohai Strait. Haiyang Xuebao. 42(3), 83-96. https://doi.org/ 10.3969/j.issn.0253-4193.2020.03.008 (in Chinese with English Abstrct)

Qin, Y.-C., Xue, C., \& Jiang, X. (2018). Tidal current-dominated depositional environments in the Central-Northern Yellow Sea as revealed by heavy-mineral and grain-size dispersals. Marine Geology, 398, 59-72. https://doi.org/10.1016/j.margeo.2018.01.004 
Qu, L., Lin, X., Hetland, R. D., \& Guo, J. (2018). The asymmetric continental shelf wave in response to the synoptic wind burst in a semienclosed double-shelf basin. Journal of Geophysical Research: Oceans, 123, 131-148. https://doi.org/10.1002/2017JC013025

Saito, Y., Yang, Z., \& Hori, K. (2001). The Huanghe (Yellow River) and Changjiang (Yangtze River) deltas: A review on their characteristics, evolution and sediment discharge during the Holocene. Geomorphology, 41(2-3), 219-231. https://doi.org/10.1016/S0169-555X(01) 00118-0

Shchepetkin, A. F., \& McWilliams, J. C. (2005). The regional oceanic modeling system (ROMS): A split-explicit, free-surface, topographyfollowing-coordinate oceanic model. Ocean Modelling, 9(4), 347-404. https://doi.org/10.1016/j.ocemod.2004.08.002

Skamarock, C. W., Klemp, J., Dudhia, J. O., Gill, D., Barker, D., Wang, W., \& Powers, G. J. (2005). A description of the advanced research WRF version 2. NCAR/TN-468+STR. https://doi.org/10.5065/D68S4MVH

Song, Y., \& Haidvogel, D. (1994). A semi-implicit ocean circulation model using a generalized topography-following coordinate system. Journal of Computational Physics, 115(1), 228-244. https://doi.org/10.1006/jcph.1994.1189

Thomson, R. E., \& Emery, W. J. (2014). Data analysis methods in physical oceanography (Third ed., 715 pp.). Waltham, MA: Elsevier.

Thorne, P. D., \& Hurther, D. (2014). An overview on the use of backscattered sound for measuring suspended particle size and concentration profiles in non-cohesive inorganic sediment transport studies. Continental Shelf Research, 73, 97-118. https://doi.org/10.1016/j. csr.2013.10.017

Wan, K., Bao, X., Wang, Y., Wan, X., Li, H., \& Liu, K. (2014). Barotropic current fluctuations coupled with sea level drawdown in Yellow and Bohai seas. Chinese Journal of Oceanology and Limnology, 33(1), 272-281. https://doi.org/10.1007/s00343-015-4056-3

Wang, A., Ralston, D. K., Bi, N., Cheng, Z., Wu, X., \& Wang, H. (2019). Seasonal variation in sediment transport and deposition on a muddy clinoform in the Yellow Sea. Continental Shelf Research, 179, 37-51. https://doi.org/10.1016/j.csr.2019.04.009

Wang, D.-P., \& Elliott, A. (1978). Non-tidal variability in the Chesapeake Bay and Potomac River: Evidence for nonlocal forcing. Journal of Physical Oceanography, 8(2), 225-232. https://doi.org/10.1175/1520-0485(1978)008<0225:NTVITC >2.0.CO;2

Warner, J. C., Armstrong, B., He, R., \& Zambon, J. B. (2010). Development of a Coupled Ocean-Atmosphere-Wave-Sediment Transport (COAWST) modeling system. Ocean Modelling, 35(3), 230-244. https://doi.org/10.1016/j.ocemod.2010.07.010

Warner, J. C., Butman, B., \& Dalyander, P. S. (2008a). Storm-driven sediment transport in Massachusetts Bay. Continental Shelf Research, 28(2), 257-282. https://doi.org/10.1016/j.csr.2007.08.008

Warner, J. C., Sherwood, C. R., Signell, R. P., Harris, C. K., \& Arango, H. G. (2008b). Development of a three-dimensional, regional, coupled wave, current, and sediment-transport model. Computers \& Geosciences, 34(10), 1284-1306. https://doi.org/10.1016/j.cageo.2008.02.012

Whitehouse, R., Soulsby, R., Roberts, W. \& Mitchener, H. (2000). Dynamics of estuarine muds: a manual for practical applications, London: Thomas Telford. https://doi.org/10.1680/doem.28647.0005

Willmott, C. J. (1981). On the validation of models. Physical Geography, 2(2), 184-194. https://doi.org/10.1080/02723646.1981.10642213

Wright, D. G., Greenberg, D. A., \& Majaess, F. G. (1987). The influence of bays on adjusted sea level over adjacent shelves with application to the Labrador shelf. Journal of Geophysical Research, 92(C13), 14,610-14,620. https://doi.org/10.1029/JC092iC13p14610

Wright, L. D., Xu, J. P., \& Madsen, O. S. (1994). Across-shelf benthic transports on the inner shelf of the Middle Atlantic Bight during the "Halloween storm" of 1991. Marine Geology, 118(1-2), 61-77. https://doi.org/10.1016/0025-3227(94)90113-9

Wu, X., Wu, H., Wang, H., Bi, N., Duan, H., Wang, C., et al. (2019a). Novel, repeated surveys reveal new insights on sediment flux through a Narrow Strait, Bohai, China. Journal of Geophysical Research: Oceans, 124, 6927-6941. https://doi.org/10.1029/2019JC015293

Wu, X., Xu, J., Wu, H., Bi, N., Bian, C., Li, P., ... Wang, H. (2019b). Synoptic variations of residual currents in the Huanghe (Yellow River)derived distal mud patch off the Shandong Peninsula: Implications for long-term sediment transport. Marine Geology, 417, 106014. https://doi.org/10.1016/j.margeo.2019.106014

Xie, X., Li, M., \& Ni, W. (2018). Roles of wind-driven currents and surface waves in sediment resuspension and transport during a tropical storm. Journal of Geophysical Research: Oceans, 123, 8638-8654. https://doi.org/10.1029/2018JC014104

Xu, K., Mickey, R. C., Chen, Q., Harris, C. K., Hetland, R. D., Hu, K., \& Wang, J. (2016). Shelf sediment transport during hurricanes Katrina and Rita. Computers \& Geosciences, 90, 24-39. https://doi.org/10.1016/j.cageo.2015.10.009

Xue, C., Qin, Y., Ye, S., Laws, E. A., \& Wang, Z. (2018). Evolution of Holocene ebb-tidal clinoform off the Shandong Peninsula on East China Sea shelf. Earth-Science Reviews, 177, 478-496. https://doi.org/10.1016/j.earscirev.2017.12.012

Yang, Z., Ji, Y., Bi, N., Lei, K., \& Wang, H. (2011). Sediment transport off the Huanghe (Yellow River) delta and in the adjacent Bohai Sea in winter and seasonal comparison. Estuarine, Coastal and Shelf Science, 93(3), 173-181. https://doi.org/10.1016/j.ecss.2010.06.005

Yang, Z. S., \& Liu, J. P. (2007). A unique Yellow River-derived distal subaqueous delta in the Yellow Sea. Marine Geology, 240(1-4), 169-176. https://doi.org/10.1016/j.margeo.2007.02.008

Yin, L., Qiao, F., \& Zheng, Q. (2013). Coastal-trapped waves in the East China Sea observed by a mooring array in winter 2006. Journal of Physical Oceanography, 44(2), 576-590. https://doi.org/10.1175/JPO-D-13-07.1

Yuan, D., \& Hsueh, Y. (2010). Dynamics of the cross-shelf circulation in the Yellow and East China seas in winter. Deep Sea Research Part II: Topical Studies in Oceanography, 57(19-20), 1745-1761. https://doi.org/10.1016/j.dsr2.2010.04.002

Yuan, P., Wang, H., Wu, X., \& Bi, N. (2020). Grain-Size Distribution of Surface Sediments in the Bohai Sea and the Northern Yellow Sea: Sediment Supply and Hydrodynamics. Journal of Ocean University of China, 19(3), 589-600. https://doi.org/10.1007/s11802-020-4221-y

Zeng, X., He, R., Xue, Z., Wang, H., Wang, Y., Yao, Z., et al. (2015). River-derived sediment suspension and transport in the Bohai, Yellow, and East China seas: A preliminary modeling study. Continental Shelf Research, 111, 112-125. https://doi.org/10.1016/j.csr.2015.08.015

Zhang, Z., Qiao, F., Guo, J., \& Guo, B. (2018). Seasonal changes and driving forces of inflow and outflow through the Bohai Strait. Continental Shelf Research, 154, 1-8. https://doi.org/10.1016/j.csr.2017.12.012

Zhao, P., \& Jiang, W. (2011). A numerical study of storm surges caused by cold-air outbreaks in the Bohai Sea. Natural Hazards, 59(1), 1-15. https://doi.org/10.1007/s11069-010-9690-7 